\title{
TANDEM MASS SPECTROMETRY STRATEGIES FOR PHOSPHOPROTEOME ANALYSIS
}

\author{
Amanda M. Palumbo, ${ }^{1}$ Scott A. Smith, ${ }^{1}$ Christine L. Kalcic, ${ }^{1}$ Marcos Dantus, ${ }^{1,2}$ \\ Paul M. Stemmer, ${ }^{3}$ and Gavin E. Reid ${ }^{1,4}$ * \\ ${ }^{1}$ Department of Chemistry, Michigan State University, East Lansing, \\ Michigan 48824 \\ ${ }^{2}$ Department of Physics and Astronomy, Michigan State University, \\ East Lansing, Michigan 48824 \\ ${ }^{3}$ Institute of Environmental Health Sciences, Wayne State University, \\ Detroit, Michigan 48201 \\ ${ }^{4}$ Department of Biochemistry and Molecular Biology, \\ Michigan State University, East Lansing, Michigan 48824
}

Published online 3 February 2011 in Wiley Online Library (wileyonlinelibrary.com). DOI 10.1002/mas.20310

Protein phosphorylation is involved in nearly all essential biochemical pathways and the deregulation of phosphorylation events has been associated with the onset of numerous diseases. A multitude of tandem mass spectrometry (MS/MS) and multistage $M S / M S\left(\right.$ i.e., $\left.M S^{n}\right)$ strategies have been developed in recent years and have been applied toward comprehensive phosphoproteomic analysis, based on the interrogation of proteolytically derived phosphopeptides. However, the utility of each of these MS/MS and $M S^{n}$ approaches for phosphopeptide identification and characterization, including phosphorylation site localization, is critically dependant on the properties of the precursor ion (e.g., polarity and charge state), the specific ion activation method that is employed, and the underlying gas-phase ion chemistries, mechanisms and other factors that influence the gas-phase fragmentation behavior of phosphopeptide ions. This review therefore provides an overview of recent studies aimed at developing an improved understanding of these issues, and highlights the advantages and limitations of both established (e.g., CID) and newly maturing (e.g., ECD, ETD, photodissociation, etc.) yet complementary, ion activation techniques. This understanding is expected to facilitate the continued refinement of existing MS/MS strategies, and the development of novel MS/ $M S$ techniques for phosphopeptide analysis, with great promise in providing new insights into the role of protein phosphorylation on normal biological function, and in the onset and progression of disease. (C) 2011 Wiley Periodicals, Inc., Mass Spec Rev 30:600-625, 2011

Keywords: phosphorylation; phosphopeptide; phosphoproteome; tandem mass spectrometry; gas-phase ion chemistry; mechanisms

\section{INTRODUCTION}

Protein phosphorylation is perhaps the most pervasive posttranslational modification (PTM), playing an essential role in the coordination and regulation of virtually all cellular processes (Cohen, 2000; Hunter, 2000). Since the genome does not encode for protein phosphorylation directly, phosphorylation events are

*Correspondence to: Gavin E. Reid, Department of Chemistry, Michigan State University, 229 Chemistry Building, East Lansing, MI 48824. E-mail: reid@chemistry.msu.edu dynamic and reflect the current physiological needs of a cell. Accordingly, protein phosphorylation is reversible, whereby phosphorylation by kinases and dephosphorylation by phosphatases serves to regulate protein activity, expression levels, sub-cellular localization, and protein-protein interactions. Due to its broad biological importance, it is not surprising that deregulation of phosphorylation events has been associated with the onset and progression of many pathological conditions (Bode \& Dong, 2004; Culmsee \& Landshamer, 2006; Kewalramani et al., 2007; Mackay \& Twelves, 2007; Mazanetz \& Fischer, 2007; Frawley Cass et al., 2010). Therefore, understanding protein phosphorylation on a molecular level has been of great interest towards understanding the difference between "healthy" and "abnormal" cellular states, as well as for opening new avenues of disease therapy (Clark \& Bookland, 2005; Ducruet et al., 2005; Gong et al., 2006; Gong \& Iqbal, 2008; Frawley Cass et al., 2010).

Due to the elaborate nature of protein phosphorylation, its analysis presents a formidable challenge. For example, since phosphorylation is a transient modification, the lifetime of a phosphorylated site may be short and therefore the associated structure may be difficult to "capture" for analysis. Furthermore, a particular phosphorylated form of a protein may be substoichiometric, meaning that only a small fraction of the population of a particular protein may be phosphorylated at any given time. Moreover, differentially phosphorylated isoforms (i.e., different sites of phosphorylation) of a given protein may also exist simultaneously in this substoichiometric population. The sheer number of potential phosphorylation sites across the proteome also complicates their analysis. In eukaryotes, phosphorylation predominantly occurs on serine, threonine, and tyrosine residues (Fig. 1), which represent approximately $17 \%$ of the total amino acid content in an average protein (Echols et al., 2002). Based on this fact it has been calculated that in an average eukaryotic cell, there exists nearly 700,000 different potential phosphorylation sites (Ubersax \& Ferrell, 2007).

To overcome these inherent biological challenges, numerous mass spectrometry (MS) based approaches have been developed, and have now become the methods of choice for the identification and characterization of an individual phosphoprotein or for the comprehensive examination of an entire "phosphoproteome" from a given tissue, cell or sub-cellular 


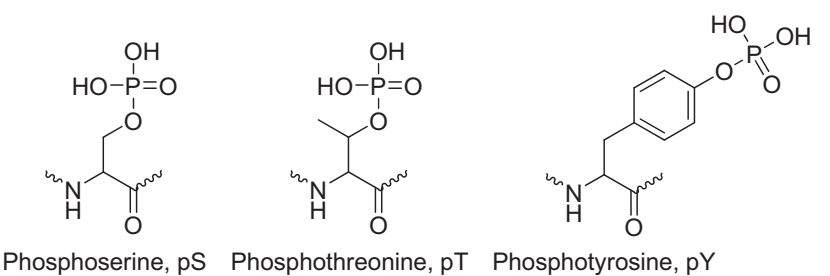

FIGURE 1. Structures of phosphorylated serine, threonine and tyrosine residues.

fraction under a given set of physiological or pathological conditions (McLachlin \& Chait, 2001; Mann \& Jensen, 2003; Carr, Annan, \& Huddleston, 2005; Goshe, 2006; Nita-Lazar, Saito-Benz, \& White, 2008; Paradela \& Albar, 2008; Boersema et al., 2009). Phosphoproteome analysis methods are generally based on the interrogation of peptides derived from enzymatic digestion of intact phosphoproteins, that is, the "bottom-up approach." For complex biological mixtures, peptide digests are typically fractioned off- or on-line by chromatographic separation techniques (e.g., reversed phase high performance liquid chromatography, RP-HPLC) prior to their introduction to the mass spectrometer (Zugaro et al., 1998). To address challenges associated with the analysis of low abundance phosphoproteins or substoichiometric phosphorylation, phosphopeptides are typically further enriched prior to RP-HPLC and mass spectrometry analysis. Many different techniques are available for this purpose, including immunoaffinity chromatography (Rush et al., 2005), ion exchange chromatography (Olsen et al., 2006; Macek et al., 2007; Bergström Lind et al., 2008; Zanivan et al., 2008), immobilized metal ion affinity chromatography (IMAC; Andersson \& Porath, 1986; Posewitz \& Tempst, 1999; Ficarro et al., 2002; Kokubu et al., 2005), metal oxide affinity chromatography (MOAC; Matsuda, Nakamura, \& Nakajima, 1990; Ikeguchi \& Nakamura, 1997; Pinkse et al., 2004; Larsen et al., 2005; Kweon \& Hakansson, 2006), and chemical derivatization (Meyer et al., 1986; Goshe et al., 2001; Oda, Nagasu, \& Chait, 2001; Zhou, Watts, \& Aebersold, 2001; Knight et al., 2003; McLachlin \& Chait, 2003; Thaler et al., 2003; Lansdell \& Tepe, 2004; Tao et al., 2005; Frawley Cass et al., 2009). Furthermore, enrichment on the phosphoprotein level may be employed to decrease sample complexity prior to enzymatic digestion (Pandey et al., 2000; Ficarro et al., 2003; Brill et al., 2004). Comprehensive reviews describing the development and application of these phosphopeptide and phosphoprotein enrichment methods have recently appeared elsewhere in the literature (Dunn, Reid, \& Bruening, 2010; Thingholm, Jensen, \& Larsen, 2009), and so will not be further described here. Although these sample preparation methods have undoubtedly improved phosphoproteomic analysis strategies, significant challenges remain associated with the mass spectrometry-based aspects of the phosphoproteome characterization process. In particular, the presence of the phosphate group can significantly alter the gasphase chemistry of protonated peptide ions. This ultimately impacts the effectiveness of tandem mass spectrometry (MS/MS) strategies used for phosphopeptide identification and characterization (i.e., phosphorylation site assignment). For this reason, this review focuses on providing an overview of both traditional and newly emerging MS/MS strategies employed for phosphopeptide identification and characterization. Particular attention is given to highlighting recent advances in understanding the underlying fundamental chemical principles, mechanisms and other factors that influence the gas phase fragmentation reactions associated with each of these strategies, as these issues directly influence their respective utilities. Furthermore, several of the analytical challenges that remain to be overcome in order for this important sub-discipline of the maturing field of proteomics to be used more efficiently and effectively are discussed.

\section{MASS SPECTROMETRY METHODS EMPLOYED FOR PHOSPHOPROTEOME ANALYSIS}

The major goals of mass spectrometry-based phosphoproteomic analysis are to (i) identify the presence of phosphorylated peptides, (ii) determine the identity of phosphopeptides by their amino acid sequences, (iii) localize the specific sites of phosphorylation, and (iv) quantitatively determine any temporal dependence to the phosphorylation site occupancies, under the specific biological conditions from which the phosphoprotein was isolated. These aims may be achieved by "soft" ionization of phosphopeptides followed by the use of MS, MS/MS, and multistage tandem mass spectrometry $\left(\mathrm{MS}^{n}\right)$ techniques. Each of these mass spectrometry approaches are described in detail below for phosphoproteome characterization.

\section{A. Ionization of Phosphorylated Peptides}

Introduction of phosphopeptides to the mass spectrometer is typically achieved by electrospray ionization (ESI) or matrixassisted laser desorption ionization (MALDI). The use of these two sources often allow complementary MS and MS/MS information to be obtained, as they produce different types of ions, that is, multiply charged ions are typically formed by ESI whereas singly charged ions are formed by MALDI. The ionization, subsequent detection and/or structural analysis of phosphopeptides by these sources may, however, be limited by the presence of extraneous peptides. It has previously been proposed that the ionization efficiency of phosphorylated peptides may be lower than their nonmodified peptide analogs using MALDI (Craig et al., 1994; Liao et al., 1994). For these reasons, the use of alternative MALDI matrices such as $2^{\prime}, 4^{\prime}, 6^{\prime}$ trihydroxyacetophenone, and a range of matrix additives such as ammonium salts and phosphoric/phosphonic acids, have been employed to enhance the phosphopeptide ionization yields (Asara \& Allison, 1999; Stensballe \& Jensen, 2004; Yang et al., 2004; Kuyama, Sonomura, \& Nishimura, 2008). The potential for decreased ionization efficiency of phosphorylated peptides versus their nonphosphorylated analogs has also been examined for ESI. However, the results of this study did not indicate selective suppression (Steen et al., 2006). Rather, it was concluded that phosphopeptide ions produced by ESI may be nonspecifically suppressed owing to their low stoichiometry (Steen et al., 2006). These results further indicate a necessity for phosphopeptide enrichment prior to MS analysis.

\section{B. MS Analysis of Phosphorylated Peptide Ions}

Perhaps the simplest method for identification of the presence of a phosphopeptide by MS is via analysis of a sample before and after phosphatase treatment (Liao et al., 1994; Larsen et al., 2001). The observed reduction in mass by $n$ multiples of $80 \mathrm{Da}$ of 
a peptide is indicative of the presence of $n$ phosphorylation sites. Additionally, the derivatization of phosphopeptides with mass tags, either in solution or in the gas phase (via ion-molecule reactions) (Meyer et al., 1986; Goshe et al., 2001; Oda, Nagasu, \& Chait, 2001; McLachlin \& Chait, 2003; Thaler et al., 2003; Tao et al., 2005; Pyatkivskyy \& Ryzhov, 2008), and subsequent MS analysis may be used to determine the presence of phosphopeptides from a mixture. Derivatization techniques have also been used for the incorporation of stable isotope labels, allowing quantitative analysis of the occupancies of phosphorylation sites (Weckwerth, Willmitzer, \& Fiehn, 2000; Goshe et al., 2001; Tao et al., 2005). All of these techniques are, however, limited to the analysis of abundant peptides and relatively simple mixtures, where the mass shift is readily observable. Thus, the majority of methods for phosphoproteome analysis rely on the use of MS/MS techniques.

\section{Tandem Mass Spectrometry and Gas Phase Ion Chemistry of Phosphorylated Peptides}

MS/MS involves the isolation and gas phase reaction (typically dissociation) of selected precursor ions, followed by mass analysis of the resultant product ions. In certain types of mass spectrometry instrumentation, product ions formed from a previous stage of reaction can be subsequently isolated and then subjected to further reaction and mass analysis. This is termed $\mathrm{MS}^{n}$ analysis, where $n$ represents the total number of isolation and mass analysis stages. A plethora of dissociation methods have been employed for the characterization of peptide ions, including collision-induced dissociation (CID; also known as collision-activated dissociation, CAD; Wells \& McLuckey, 2005), post-source decay (PSD; Spengler, 1997), infrared multi-photon dissociation (IRMPD; Brodbelt \& Wilson, 2009), ultraviolet photodissociation (UVPD; Reilly, 2009), femtosecond laser-induced ionization/dissociation (fsLID; Kalcic et al., 2009), electron capture dissociation (ECD; Cooper, Håkansson, \& Marshall, 2005), electron transfer dissociation (ETD; Wiesner, Premsler, \& Sickmann, 2008), electron ionization dissociation (EID; Fung, Adams, \& Zubarev, 2009), electronic excitation dissociation (EED; Cooper, Håkansson, \& Marshall, 2005), electron detachment dissociation (EDD; Cooper, Håkansson, \& Marshall, 2005), and metastable atomactivated dissociation (MAD; Misharin et al., 2005). Although the methods most widely employed to date for phosphoproteome analysis are CID, ECD, and ETD, the majority of the dissociation techniques defined above have each been applied to phosphopeptide identification and characterization, and are summarized in Figure 2. These MS/MS strategies have allowed for the identification of the presence of phosphorylated peptides, the identification of the phosphopeptide by its amino acid sequence, the determination of phosphorylation sites, and quantitative analyses of phosphorylation site occupancies. The merits of these various methods, used alone or in combination, are further discussed in detail throughout the remainder of this review article.

The ability to acquire such a variety of phosphoproteome information from these MS/MS techniques is ultimately dependent on the types of product ions that are formed. The possible product ions resulting from dissociation of a peptide ion along its backbone have been defined previously and are summarized in Figure 3 (Roepstorff \& Fohlman, 1984; Biemann, 1988). Briefly, dissociation can occur at the $\mathrm{C}_{\alpha}-\mathrm{C}_{\text {carbonyl }}, \mathrm{C}_{\text {carbonyl }}-\mathrm{N}$ (i.e., amide), or $\mathrm{N}-\mathrm{C}_{\alpha}$ bonds to give rise to $\mathrm{a}-, \mathrm{b}-$, or c-type "sequence" product ions if the charge is retained on the $\mathrm{N}$-terminal segment and $\mathrm{x}-$, $\mathrm{y}$-, or $\mathrm{z}$-type "sequence" product ions if the charge is retained on the $C$-terminal segment. Therefore, if a population of precursor peptide ions dissociate to produce a series of consecutive a-, b-, c-, x-, y-, or z-type ions, the amino acid sequence of the peptide may be determined from the difference between these consecutive ions, including determination of the identity and the site of phosphorylation (Horn, Ge, \& McLafferty, 2000a; Horn, Zubarev, \& McLafferty, 2000b; Matthiesen et al., 2005; Nielsen, Savitski, \& Zubarev, 2005; Beausoleil et al., 2006; Olsen et al., 2006; Lu et al., 2007; Wan et al., 2008). Importantly, since the residue masses of phosphorylated serine $(167 \mathrm{Da})$, phosphorylated threonine (181 Da), and phosphorylated tyrosine (243 Da) are unique, the sequence ions of phosphorylated peptides are directly indicative of the presence of phosphopeptides and the location of the phosphorylation sites within the peptide.

In addition to backbone fragmentation reactions, the dissociation of amino acid side chains may also occur. Although these ions are not indicative of the amino acid sequence, and are therefore termed "nonsequence" ions, they may indicate the amino acid composition. In particular, some ion dissociation techniques induce selective cleavage of the phosphoester bond of phosphopeptides, resulting in the formation of nonsequence product ions which may be used to indicate the presence of a phosphorylated peptide (Fig. 2, diagnostic ions). When observed at high abundance however, the formation of these nonsequence product ions may preclude determination of the identity of the peptide and the location of phosphorylation sites. Thus, sequence and nonsequence ions each provide complementary information useful for phosphoproteome analysis.

Importantly, the properties of the precursor ion (e.g., precursor ion polarity and charge state), as well as the method by which the precursor ion is subjected to dissociation, heavily influences the applicability of a given MS/MS dissociation method, and the type (i.e., sequence vs. nonsequence), structure, and abundance of the resultant product ions that are formed. As a result, the overall success of a given MS/MS strategy to obtain analytically useful information for phosphoproteome identification and characterization is critically dependant on the underlying chemistry of the phosphopeptide dissociation technique employed (Boersema et al., 2009). The remainder of this review therefore focuses on describing the current state of knowledge regarding the gas phase ion chemistry associated with the various MS/MS methods employed to date for phosphopeptide identification and phosphorylation site assignment, and highlights the influence that gas phase ion chemistry has on the applicability of the analytical strategies used. Several reviews describing the application of MS/MS methods for quantitative phosphoproteomics have recently been published elsewhere, and therefore will not be discussed further here (Nita-Lazar, Saito-Benz, \& White, 2008; Schreiber et al., 2008).

1. Collision Induced Dissociation (CID). To date, CID (or CAD) is the most established and widely used MS/MS method employed for peptide sequencing. Many different mass analyzer 


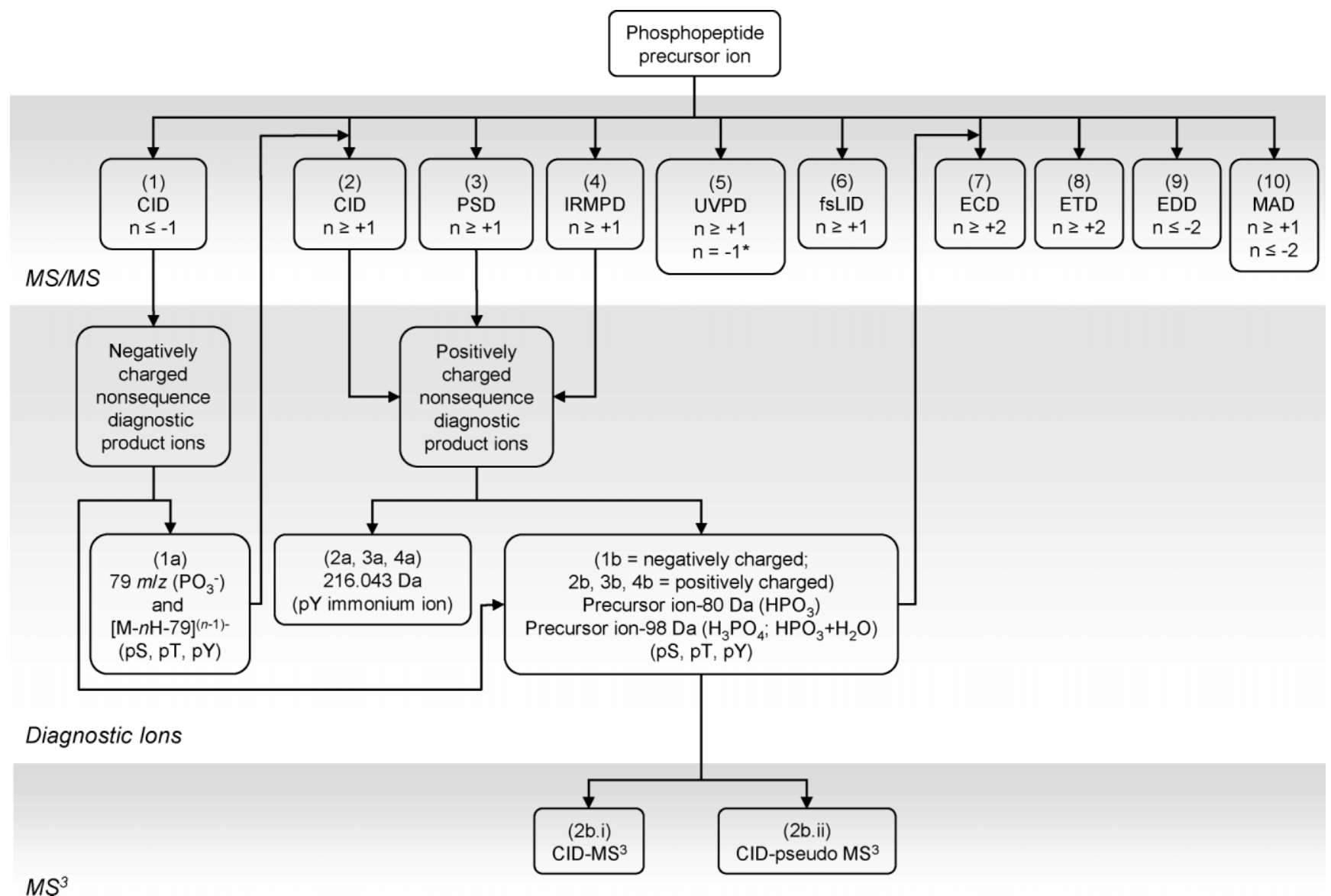

FIGURE 2. Flow chart of demonstrated tandem mass spectrometry strategies for phosphopeptide analysis. Multiple MS/MS dissociation methods have been used for the analysis of phosphopeptide precursor ions. Commonly applicable phosphopeptide precursor ion charge states $(n)$ are specified for each MS/MS technique. Some techniques, namely CID-, PSD-, and IRMPD-MS/MS, may involve formation of nonsequence product ions that diagnostically indicate the presence of phosphorylated peptide ions (indicated with arrows connecting "MS/MS" methods to "diagnostic ions"). Observation of these diagnostic product ions has also been used to trigger precursor ion activation by other MS/MS methods (i.e., ECD) or MS/MS activation of the resultant neutral loss product ion (e.g., $\mathrm{MS}^{3}$; indicated with arrows connecting "diagnostic ions" to "MS/MS" or "MS" methods).

platforms are compatible with CID, including quadrupole ion trap (QIT) and Fourier transform ion cyclotron resonance (FTICR) mass spectrometers. Additionally, utilization of quadrupole-based collision cells allow for CID-MS/MS in triple quadrupole (QqQ), quadrupole time of flight (qTOF), and TOF/ TOF instruments.

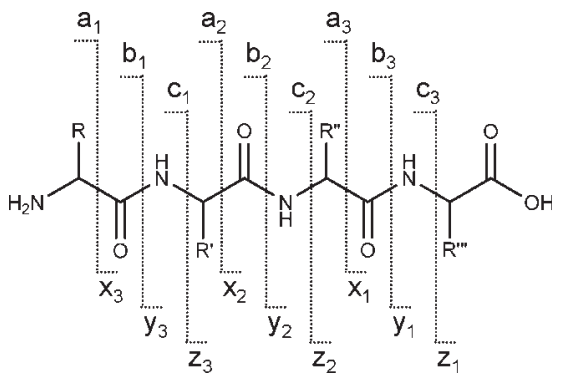

FIGURE 3. Nomenclature of peptide backbone fragment ions or sequence ions.
Ion activation during CID occurs by conversion of ion translational energy into internal (vibrational) energy upon collision with an inert target gas (e.g., He or Ar). The acquired vibrational energy is then quickly redistributed throughout all modes of the ion $\left(\leq 10^{-12} \mathrm{sec}\right)$ such that ergodic fragmentation of a particular bond occurs only when the vibrational energy exceeds the activation barrier of that bond (McLuckey \& Goeringer, 1997). Since CID is under kinetic control and is a "slow heating" process, the most labile bonds fragment preferentially (McLuckey \& Goeringer, 1997). CID of nonphosphorylated peptides generally leads to non-selective fragmentation, forming $b-$ and $y$-type sequence ions via fragmentation of amide bonds along the peptide backbone (activation energy barrier for amide bond cleavage $\sim 40 \mathrm{kcal} / \mathrm{mol}$ cleavage; Paizs et al., 1999; Csonka et al., 2000). Phosphorylated peptide ions, however, often undergo selective and preferential fragmentation at the phosphate group (activation energy barrier for phosphoester bond cleavage $<20 \mathrm{kcal} / \mathrm{mol}$; Reid, Simpson, \& O'Hair, 2000; Flora \& Muddiman, 2004; Gronert, Li, \& 
Horiuchi, 2005), giving rise to nonsequence neutral losses from the precursor ion of $80 \mathrm{Da}\left(\mathrm{HPO}_{3}\right)$ and $98 \mathrm{Da}\left(\mathrm{H}_{3} \mathrm{PO}_{4}\right.$ or $\left.\mathrm{H}_{2} \mathrm{O}+\mathrm{HPO}_{3}\right)$, or charged losses of $63 \mathrm{Da}\left(\mathrm{PO}_{2}{ }^{-}\right), 79 \mathrm{Da}$ $\left(\mathrm{PO}_{3}{ }^{-}\right)$, and $97 \mathrm{Da}\left(\mathrm{H}_{2} \mathrm{PO}_{4}{ }^{-}\right)$, as well as nonsequence neutral losses from sequence type product ions via sequential fragmentation reactions (Huddleston et al., 1993; Ding, Burkhart, \& Kassel, 1994; Carr, Huddleston, \& Annan, 1996; DeGnore \& Qin, 1998; Tholey, Reed, \& Lehmann, 1999; Schlosser et al., 2001; Moyer, Cotter, \& Woods, 2002; Collins et al., 2005; Edelson-Averbukh, Pipkorn, \& Lehmann, 2006; Ndassa et al., 2006; Olsen et al., 2006; Li et al., 2007; Macek et al., 2007).

CID-MS/MS has been used for the identification of phosphopeptides and localization of phosphorylation sites in both positive and negative ion modes (Fig. 2(1) and (2), respectively). The gas phase ion chemistries governing these CID-MS/MS techniques as well as their impact on the utility of these methods are described in detail below.

a. Formation of $79 \mathrm{~m} / \mathrm{z}\left(\mathrm{PO}_{3}{ }^{-}\right)$and $[\mathrm{M}+n \mathrm{H}-79]^{(n-1)-}$ Ions. CID of negatively charged phospho-serine, -threonine, and-tyrosine peptide precursor ions commonly result in cleavage of the phosphoester bond, giving rise to $\mathrm{PO}_{3}{ }^{-}$ions $(\mathrm{m} / \mathrm{z}, 79)$. When the precursor ion is multiply deprotonated, a charge reduced counterpart ion $\left([M-n \mathrm{H}-79]^{(n-1)-}\right)$ may also be observed. A mechanism for the formation of these ions has been previously proposed, and is shown in Scheme 1 for a doubly deprotonated precursor ion (Huddleston et al., 1993; Ding, Burkhart, \& Kassel, 1994; Tholey, Reed, \& Lehmann, 1999; Edelson-Averbukh, Pipkorn, \& Lehmann, 2006).

The observation of the $m / z 79 \mathrm{PO}_{3}{ }^{-}$product ion has been used to indicate the presence of phosphorylated peptides (Fig. 2(1a); Huddleston et al., 1993; Ding, Burkhart, \& Kassel, 1994). Since $m / z 79$ may be too low to be observed in ion trap platforms under typical peptide analysis conditions, due to the inherent low mass cutoff associated with product ion stability in this type of instrumentation, the $[M+n \mathrm{H}-79]^{(n-1)-}$ product ion may alternatively be used for phosphopeptide detection (Fig. 2(1a); Edelson-Averbukh, Pipkorn, \& Lehmann, 2006). Additionally, the observation of these nonsequence product ions in negative ion mode, via dissociation of the deprotonated precursor ions, has been used to trigger the acquisition of a positive ion mode CID-MS/MS spectrum of the corresponding protonated precursor ion for phosphopeptide sequence analysis and phosphorylation site characterization (Fig. 2(1a) followed by Fig. 2(2)). This has been achieved by either polarity switching during sample analysis or by performing a second round of analysis in positive ion mode (Carr, Huddleston, \& Annan, 1996; Annan et al., 2001; Collins et al., 2005). An example of the utility

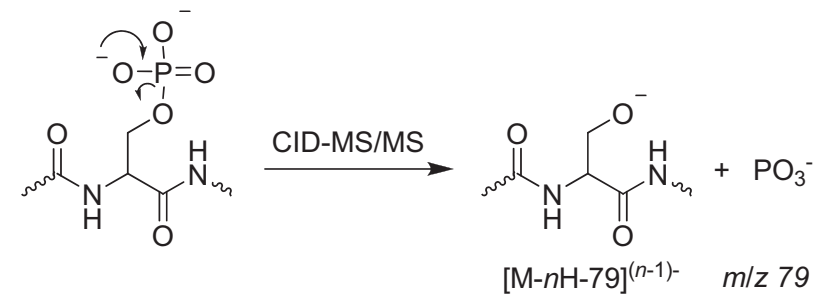

SCHEME 1. Previously proposed mechanism for cleavage of the $\mathrm{P}-\mathrm{O}$ phosphoester bond of negatively charged phosphorylated peptides forming $[M-n \mathrm{H}-79]^{(n-1)-}$ and $\mathrm{PO}_{3}{ }^{-}(\mathrm{m} / \mathrm{z}, 79)$. of this technique is illustrated in Figure 4. Selected ion monitoring for $\mathrm{PO}_{3}{ }^{-}$at $\mathrm{m} / \mathrm{z}, 79$ using a triple quadrupole mass spectrometer during on-line LC-ESI-MS of a trypsin digest of Sic1p that was phosphorylated in vitro, was used to initially localize the presence of phosphopeptides within the chromatographic elution profile (gray trace in Fig. 4A). Then, a precursor ion scan mode MS/MS experiment to monitor for the presence of the characteristic $\mathrm{PO}_{3}{ }^{-}$ion at $\mathrm{m} / \mathrm{z}, 79$ was used to identify the $\mathrm{m} / \mathrm{z}$ of the deprotonated phosphopeptide precursor ions (Fig. 4B) within the fraction labeled with a* in panel A. Finally, the mass spectrometer was switched to positive ion mode and the sequences of individual protonated phosphopeptide precursor ions were determined following acquisition of a product ion CIDMS/MS spectrum (Fig. 4C; Annan et al., 2001).

b. Formation of phosphotyrosine-specific immonium ions at $\mathrm{m} / \mathrm{z}$ 216.043. In positive ion mode, CID-MS/MS of protonated phosphotyrosine-containing peptide ions can give rise to a

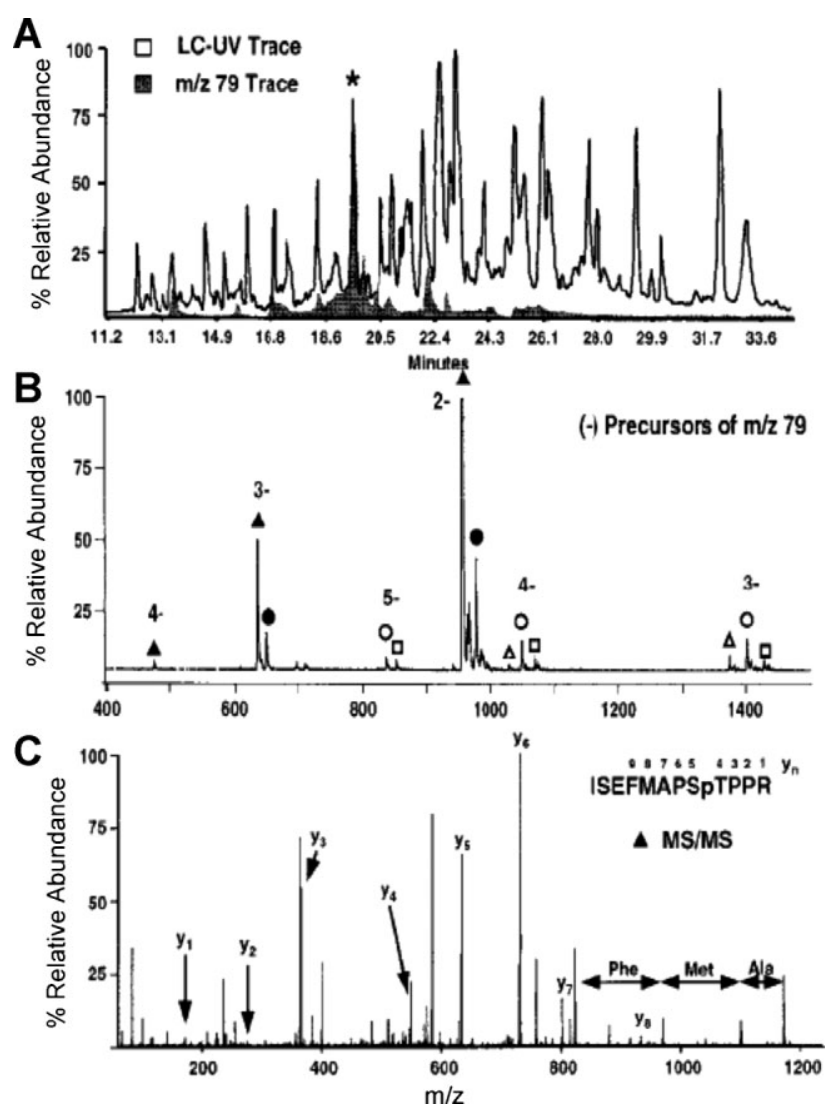

FIGURE 4. Multidimensional electrospray MS mapping of in vitro phosphorylation of Sic1p, a regulator of the G1/S transition in budding yeast using a triple quadrupole mass spectrometer. A: HPLC-ESI-MS selected ion monitoring trace for $\mathrm{m} / \mathrm{z} 79$ overlaid with the HPLC-UV trace of a tryptic digest of purified phosphorylated Sic1p. B: Negative ion mode precursor ion ESI-MS scan for $m / z, 79$ of the LC-MS-fractionated material marked with an "*" in the chromatogram shown in panel A. The presence of five phosphopeptides, each marked with a unique symbol, were identified in this fraction. C: Positive ion mode CID-MS/MS product ion spectrum of $\mathrm{m} / \mathrm{z}$ 637.6, the triply charged ion for the 1909.8 Da phosphopeptide marked with a " $\boldsymbol{\Delta}$ " in panel B. Reproduced from Annan et al. (2001) with permission from American Chemical Society, copyright 2001 . 


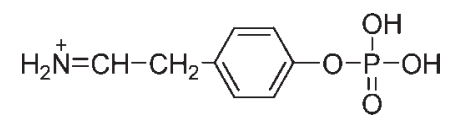

FIGURE 5. Structure of the phosphotyrosine-specific immonium ion, $\mathrm{m} / \mathrm{z}, 216.043$.

phosphotyrosine specific nonsequence immonium ion at $\mathrm{m} / \mathrm{z}$ 216.043 (Fig. 5; Steen et al., 2001a; Steen, Kuster, \& Mann, 2001b). Immonium ions provide composition-specific information and may result from cleavage of the $N$-terminal residue or from two backbone cleavages surrounding a particular internal residue. It has been previously shown that the abundance of the phosphotyrosine (pY) immonium ion is dependent upon the sequence of the peptide (Salek et al., 2003), and that the immonium ion abundance is highest when the phosphotyrosine residue is located at the first or second residue from the $N$-terminus (Salek et al., 2003). This is in accordance with the observation that $\mathrm{N}$-terminal residues generally favor the formation of immonium ions (Ambihapathy et al., 1997; Hohmann et al., 2008). Additionally, since immonium ions may be formed via secondary fragmentation of $b_{n}$ sequence ions and $b_{2}$ ion formation is favored, the second position from the $N$-terminus may also preferentially form these ions (Ambihapathy et al., 1997; Hohmann et al., 2008). Furthermore, a fragmentation study on a series of synthetic phosphopeptides with the general sequence DQQDFFPK where $\mathrm{pY}$ was placed in positions 1-9 demonstrated that the closer the $\mathrm{pY}$ residue was to the $C$-terminal lysine, the less likely the corresponding immonium ion was to form (Salek et al., 2003).

Precursor ion scanning to monitor formation of the $\mathrm{pY}$ immonium ion has been used for selective detection of phosphotyrosine-containing peptides from mixtures (Fig. 2(2a), (3a), (4a); Steen et al., 2001a, 2002; Steen, Kuster, \& Mann, 2001b). Since this diagnostic ion may have the same nominal mass as other ions $(216 \mathrm{Da})$, this technique has proven most effective when using high resolution/high mass accuracy instruments such as a qTOF (Steen et al., 2001a, 2002; Steen, Kuster, \& Mann, 2001b). The utility of this technique is demonstrated in Figure 6, where the identification of a low abundance phosphotyrosine-containing peptide on a qTOF instrument was facilitated by monitoring for the formation of the phosphotyrosine-specific immonium ion from a peptide mixture obtained from a HPLC fraction of an in-gel trypsin digestion from a protein band of epidermal growth factor (EGF)-activated HeLa cells (the positive ion mode MS spectrum is shown in Fig. 6A, whereas the phosphotyrosine specific immonium ion (PSI) scan is shown in Fig. 6B; Steen et al., 2002) The identity of the phosphopeptide was subsequently determined from the CID-MS/ MS product ion spectrum collected in positive ion mode of the precursor ion identified in panel B (data not shown).

c. Product ions formed from 80 or $98 \mathrm{Da}$ neutral losses. The analysis of peptides containing phospho-serine, -threonine, and/ or -tyrosine residues by CID-MS/MS in either positive or negative ion mode may give rise to nonsequence product ions corresponding to the neutral losses of $80 \mathrm{Da}\left(\mathrm{HPO}_{3}\right)$ and $98 \mathrm{Da}$ (commonly assigned as $\mathrm{H}_{3} \mathrm{PO}_{4}$; Carr, Huddleston, \& Annan, 1996; DeGnore \& Qin, 1998; Tholey, Reed, \& Lehmann, 1999;

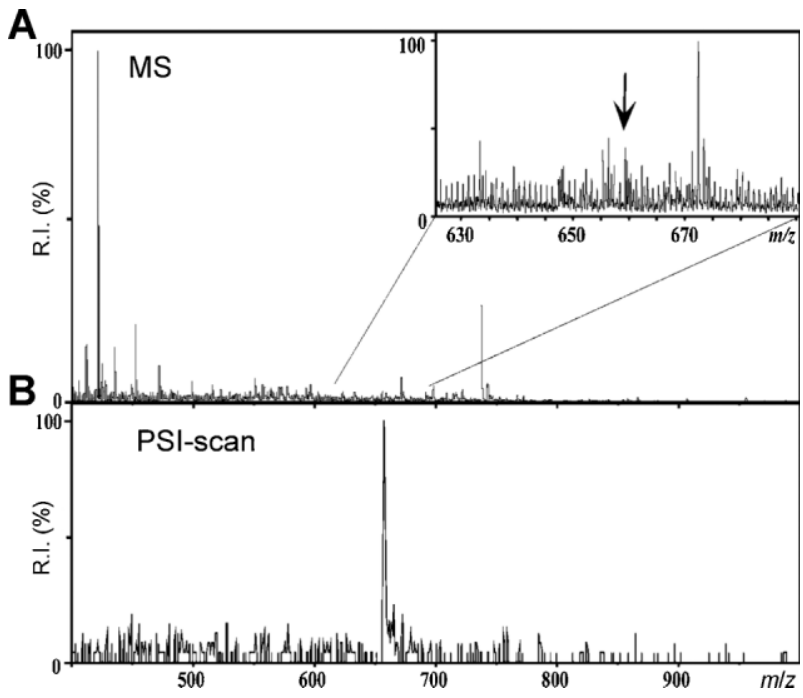

FIGURE 6. A: MS spectrum collected in positive ion mode of an HPLC fraction of an in-gel trypsin digest of an immunoaffinity-purified phosphotyrosine protein from EGF stimulated HeLa cells. B: Phosphotyrosine specific immonium ion (PSI) scan on a qTOF resulting in the observation of one phosphopeptide at $m / z$ 659.3, whose identity was determined to be ELFDDPSpYVNVQNLDK from Shc protein from the full scan positive ion mode CID-MS/MS spectrum (data not shown). Note that the inset to panel $\mathrm{A}$ is an expanded view of the region of the MS scan that contains the phosphopeptide at $\mathrm{m} / \mathrm{z}$ 659.3. Reproduced from Steen et al. (2002) with permission from The American Society for Biochemistry and Molecular Biology, copyright 2002.

Schlosser et al., 2001; Moyer, Cotter, \& Woods, 2002; Olsen et al., 2006; Li et al., 2007; Macek et al., 2007) from the precursor ions, yielding $[M-n \mathrm{H}-80]^{n-},[M-n \mathrm{H}-98]^{n-},[M+n \mathrm{H}-80]^{n+}$, and $[M+n \mathrm{H}-80]^{n+}$ products that diagnostically indicate the presence of a phosphorylated peptide ion (Fig. 2(1b), (2b), (3b), and (4b)), as well as nonsequence losses from sequence type product ions (e.g., $\mathrm{b}_{n^{-}} 80, \mathrm{~b}_{n^{-}}-98, \mathrm{y}_{n^{-}}-80$, and $\mathrm{y}_{n}-98$ ) via sequential fragmentation reactions of the peptide backbone and the phospho-amino acid side chains (Moon, Shin, \& Kim, 2009).

Chemistry of the 80 and 98 Da neutral loss product ions.

The facile formation of phosphate group specific neutral loss nonsequence product ions can result in the loss of sequence information, potentially compromising the ability to identify the sequence of the phosphopeptide or to localize the phosphorylation site to a specific residue within the peptide sequence.

For this reason, the factors that govern the abundance of these neutral loss product ions have been the subject of extensive examination. In particular, it has been noted that the neutral loss product ions are more abundant at higher collision energies (Schlosser et al., 2001; Hoffman et al., 2006), and in mass spectrometers that deposit internal energy within a short activation timescale (e.g., $\mu \mathrm{sec}$ ), such as in triple quadrupole instruments (Lehmann et al., 2007). The identity (i.e., structure) of the phosphorylated amino acid also affects the extent to which the various neutral loss product ions are observed by CID. For example, phosphotyrosine undergoes the neutral loss of $80 \mathrm{Da}$ more frequently than $98 \mathrm{Da}$ (DeGnore \& Qin, 1998; Tholey, Reed, \& Lehmann, 1999), and phosphoserine and phosphothreonine are subject to the neutral loss of $98 \mathrm{Da}$ more frequently than the loss of $80 \mathrm{Da}$ (DeGnore \& Qin, 1998; Tholey, 
Reed, \& Lehmann, 1999). The precursor ion charge state is also known to influence the abundance of the $98 \mathrm{Da}$ neutral loss product ions, whereby higher charge states result in lower phosphate neutral loss product ion abundance (DeGnore \& Qin, 1998; Tholey, Reed, \& Lehmann, 1999; Villen, Beausoleil, \& Gygi, 2008). More recently, this effect has been shown to be not solely dependent on charge state, but instead depends on a combination of charge state and basic amino acid residue composition, or "proton mobility" (Palumbo, Tepe, \& Reid, 2008). The mobile proton model has emerged as a central concept to rationalize the gas-phase fragmentation reactions of protonated peptide ions (Cox et al., 1996; Dongre et al., 1996; Wysocki et al., 2000). Briefly, fragmentation of most peptide amide backbone bonds is generally agreed to require the involvement of a proton at the cleavage site, that is, that the cleavages are "charge-directed." However, when the ionizing proton(s) are "sequestered" at the side chains of arginine, lysine or histidine amino acids (i.e., the most basic site(s) within the peptide), more energy may be required to "mobilize" the proton from the basic side chains to the peptide backbone to induce "charge-directed" dissociation, compared to that required to initiate "charge remote" fragmentation pathways (i.e., where the proton is not involved in the fragmentation mechanism). As a result, the extent of proton mobility within a protonated peptide ion dictates the type and abundance of the product ions that are formed. Three subcategories of proton mobility have been defined (Kapp et al., 2003). Precursor peptide ions are termed "nonmobile" when the number of ionizing protons is less than or equal to the number of arginine residues; "partially mobile" when the number of ionizing protons is greater than the number of arginine residues, but less than the sum of basic residues (i.e., arginine, histidine and lysine residues); or "mobile" when the number of ionizing protons is greater than the sum of basic residues. For phosphorylated peptides, the abundance of product ions corresponding to the neutral loss of $98 \mathrm{Da}$ have been shown to exhibit a strong inverse correlation with proton mobility (nonmobile $\gg$ partially mobile $>$ mobile; Palumbo, Tepe, \& Reid, 2008). For example, Figure 7 shows the product ion spectra obtained by ESI-CID-MS/MS of the singly, doubly, and triply protonated precursor ions of the synthetic di-phosphorylated peptide HEVSASpTQpSTPASSR. The magnitude of the $98 \mathrm{Da}$ neutral loss product ions (summed for -98 and -196 Da ions) under nonmobile proton conditions (panel A) was found to represent $44 \%$ of the total product ion abundance, whereas the abundances under partially mobile (panel B) and mobile proton conditions (panel C) were $27 \%$ and $24 \%$, respectively. Note that for this example, the magnitude of the processes involving side chain losses of the phosphorylated amino acid residues are actually greater than the numbers above imply, as the sequential loss of $98 \mathrm{Da}$ and water $(116 \mathrm{Da})$ and the sequential loss of $98 \mathrm{Da}$ and $\mathrm{HPO}_{3}(178 \mathrm{Da})$ are also observed as abundant product ion fragmentation pathways, in addition to the losses of 98 and 196 Da. Consistent with the findings described above, Woods and co-workers have also previously shown that the neutral loss of $98 \mathrm{Da}$ from phosphotyrosine-containing peptides is highly dependent upon the presence of basic residues, where the neutral loss was observed only when arginine and lysine residues were present within the peptide (Moyer, Cotter, \& Woods, 2002).

Given that the abundance of product ions resulting from the neutral loss of $98 \mathrm{Da}$ increase with decreasing proton mobility, it is logical to expect that the ionizing protons would be sequestered at the basic amino acid side chains (the sites with the highest local proton affinity) and therefore would not be available for participation in the phosphate group fragmentation reaction. Accordingly, a mechanism for the neutral loss of $\mathrm{H}_{3} \mathrm{PO}_{4}(98 \mathrm{Da})$ from protonated phosphoserine- and phosphothreonine-containing peptide ions has previously been proposed to occur by a charge-remote $\beta$-elimination mechanism (Scheme 2A; DeGnore \& Qin, 1998; Tholey, Reed, \& Lehmann, 1999). This mechanism involves transfer of the hydrogen atom on the $\mathrm{C}_{\alpha}$ of the phosphoamino acid residue to the phosphate oxygen, via a six-centered transition state, resulting in formation of a dehydroalanine (69 Da) or dehydroaminobutyric acid (83 Da) containing product ions from phosphorylated serine or threonine residues, respectively. Note that the ionizing proton is distant from the fragmentation site and is therefore uninvolved in the mechanism. Two alternate mechanisms have since been proposed, involving localization of the ionizing proton at the site of fragmentation, (i.e., “charge-directed"; Reid, Simpson, \& O'Hair, 2000; Gronert, Li, \& Horiuchi, 2005). The first involves a chargedirected intramolecular E2 mechanism (Scheme 2B), whereby the ionizing proton located on the phosphate weakens the $\mathrm{C}-\mathrm{O}$ phosphate ester bond, enabling abstraction of the hydrogen atom on the $\mathrm{C}_{\alpha}$ of the phospho-amino acid residue with subsequent $\mathrm{H}_{3} \mathrm{PO}_{4}$ loss by a neighboring nucleophile. Similar to the chargeremote $\beta$-elimination mechanism in Scheme $2 \mathrm{~A}$, the product ions formed in this case would also contain dehydroalanine or dehydroaminobutyric acid, for phosphoserine or phosphothreonine peptides, respectively. Note however, that the site of protonation within the product ion in Scheme $2 \mathrm{~B}$ is on the peptide backbone, but would be located at the initial site of protonation in the product ion formed via Scheme 2A. The second of the previously proposed charge-directed mechanisms involves an intramolecular $S_{N} 2$ reaction, whereby nucleophilic attack by a neighboring carbonyl group on the $\beta$-carbon of the protonated phosphorylated residue results in the loss of $\mathrm{H}_{3} \mathrm{PO}_{4}$ and the formation of an oxazoline containing product ion at the formerly phosphorylated residue (Scheme 2C).

Several studies have previously been completed to evaluate which of these mechanisms are operating for the neutral loss of $\mathrm{H}_{3} \mathrm{PO}_{4}$ from phosphoserine or phosphothreonine containing peptides (Tholey, Reed, \& Lehmann, 1999; Reid, Simpson, \& O'Hair, 2000; Palumbo, Tepe, \& Reid, 2008). Specifically, the pathways have been distinguished by using hydrogen-deuterium exchange experiments to follow the movement of the hydrogen atom originally located on the $\mathrm{C}_{\alpha}$ position of the phosphorylated amino acid residue. Notice that in the charge-remote $\beta$-elimination reaction in Scheme $2 \mathrm{~A}$, the $\mathrm{C}_{\alpha}$-hydrogen atom is eliminated with the phosphate group, whereas in the chargedirected $\mathrm{E} 2$ and $\mathrm{S}_{\mathrm{N}} 2$ reactions (Scheme $2 \mathrm{~B}$ and $\mathrm{C}$, respectively) the dephosphorylated product ions retain this hydrogen atom. Thus, for peptides deuterated at all exchangeable sites (heteroatoms), the loss of $100 \mathrm{Da}$ (i.e., $\mathrm{HD}_{2} \mathrm{PO}_{4}$ ) is expected for the charge-remote $\beta$-elimination reaction, whereas the loss of $\mathrm{D}_{3} \mathrm{PO}_{4}$ $(101 \mathrm{Da})$ is expected for the charge-directed E2 and $\mathrm{S}_{\mathrm{N}} 2$ reactions. Recently, an experiment of this sort, performed under conditions to ensure complete deuterium exchange, minimized back exchange and high spectral resolution, resulted in the dominant loss of $\mathrm{D}_{3} \mathrm{PO}_{4}$ from all peptides examined, thereby providing evidence in support of the charge-directed mechanisms (Palumbo, Tepe, \& Reid, 2008). Further evidence was provided by studying the fragmentation behavior of a phosphoserine 

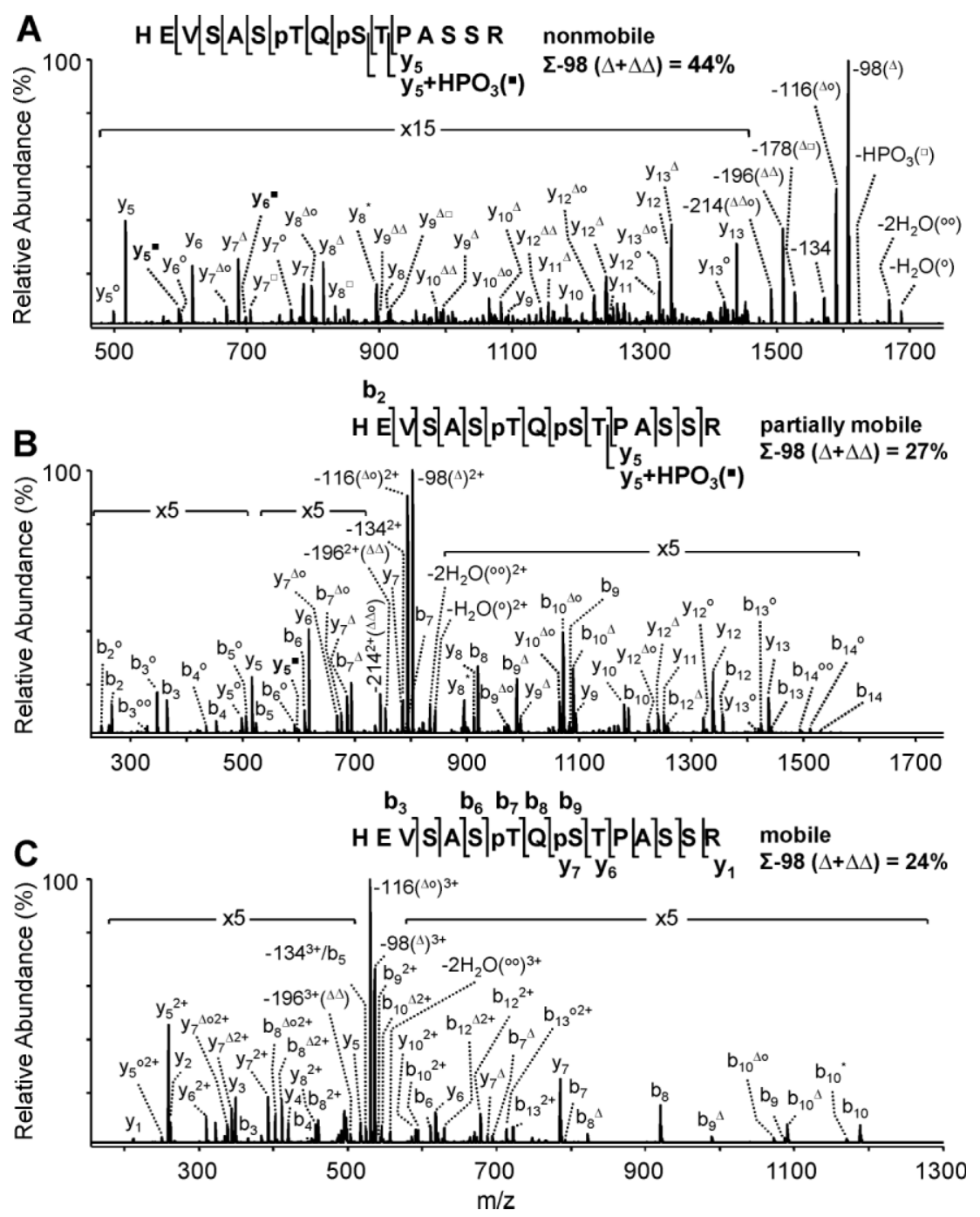

FIGURE 7. Ion trap CID-MS/MS product ion spectra of the (A) singly, (B) doubly, and (C) triply protonated precursor ions of the synthetic "tryptic" peptide HEVSASpTQpSTPASSR. No ions were observed above $1,300 \mathrm{~m} / \mathrm{z}$, for panel $\mathrm{C}$ so that region is not shown. $\Delta=-98 \mathrm{Da}\left(-\mathrm{H}_{3} \mathrm{PO}_{4}\right.$ or $\left.-\left(\mathrm{HPO}_{3}+\mathrm{H}_{2} \mathrm{O}\right)\right) ; \square=-80 \mathrm{Da}\left(-\mathrm{HPO}_{3}\right) ; \bigcirc=-18 \mathrm{Da}\left(-\mathrm{H}_{2} \mathrm{O}\right) ; *=-17 \mathrm{Da}\left(\mathrm{NH}_{3}\right) ; \boldsymbol{\square}=+80 \mathrm{Da}$ $\left(+\mathrm{HPO}_{3}\right)$. The percent total product ion abundance of the summation from the product ions resulting from -98 and -196 Da neutral losses are shown.

containing peptide that had been regioselectively deuterated at the $\alpha$ - and $\beta$-carbons of the phosphoserine amino acid residue (Palumbo, Tepe, \& Reid, 2008). In this case, loss of the phosphorylated side chain by the charge-remote $\beta$-elimination mechanism would result in the loss of $\mathrm{H}_{2} \mathrm{DPO}_{4}$, whereas the loss of $\mathrm{H}_{3} \mathrm{PO}_{4}$ would result from the charge-directed mechanisms. Upon CID-MS/MS, it was clearly demonstrated that the ion corresponding to the neutral loss of $\mathrm{H}_{3} \mathrm{PO}_{4}$ was observed as the dominant fragmentation pathway ( $\sim 95 \%$ abundance), compared to the loss of $\mathrm{H}_{2} \mathrm{DPO}_{4}(\sim 5 \%$ abundance $)$, again indicating that the neutral loss had predominantly occurred by the chargedirected mechanisms (Palumbo, Tepe, \& Reid, 2008). A caveat to the "quantitative" validity of these results is that the impact of kinetic isotope effects on the relative abundance of these competing fragmentation pathways was not determined. Interestingly, the predominant loss of $\mathrm{H}_{3} \mathrm{PO}_{4}$ over $\mathrm{H}_{2} \mathrm{DPO}_{4}$ was also shown to occur independently of the amino acid composition and charge state (Palumbo, Tepe, \& Reid, 2008). CID-MS ${ }^{3}$ analysis of the initial $98 \mathrm{Da}$ neutral loss product ions provided experimental evidence for both charge-directed mechanisms. Upon $\mathrm{MS}^{3}$ dissociation, the observation of product ions resulting from cleavage on either side of the formerly phosphorylated residue provided support for the $\mathrm{E} 2$ reaction in Scheme 2B, whereas support for the $\mathrm{S}_{\mathrm{N}} 2$ reaction was provided by the observation of product ions formed by the neutral loss of either formaldehyde $\left(\mathrm{CH}_{2} \mathrm{O}, 30 \mathrm{Da}\right)$ or acetaldehyde $\left(\mathrm{CH}_{3} \mathrm{CHO}, 44 \mathrm{Da}\right)$ from phosphoserine and phosphothreonine peptides, respectively, and by the loss of $\left(\mathrm{CD}_{2} \mathrm{O}, 32 \mathrm{Da}\right)$ from the regioselectively deuterated phosphoserine peptide, from the oxazoline cyclic product ion in Scheme 2C (Palumbo, Tepe, \& Reid, 2008).

To rationalize the two ideas (i) that ionizing protons direct the $\mathrm{H}_{3} \mathrm{PO}_{4}$ neutral loss fragmentation and (ii) that fragmentation occurs more readily under limited proton mobility, it has been proposed that the protonated basic residues form strong hydrogen 


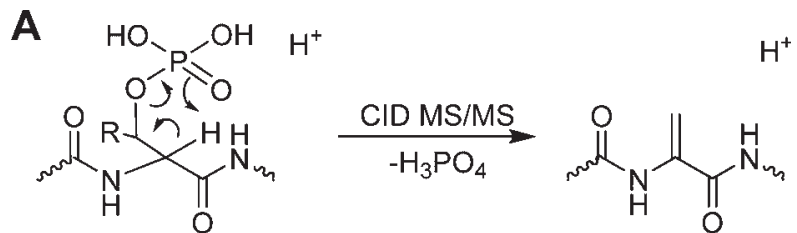<smiles>[R]C(OP(=O)(O)O)C(C)(NC(C)=O)C(=O)NC</smiles><smiles>[R]C=C(N[C+](C)O)C(=O)NC</smiles><smiles>[R]CC(NC(C)=O)C(OP(=O)(O)O)C(=O)NC</smiles><smiles>[R]C1O[C@@H](C)[NH+]=C1C(=O)NC</smiles>

SCHEME 2. Proposed mechanisms for the neutral loss of $\mathrm{H}_{3} \mathrm{PO}_{4}$ from protonated phosphoserine- or phosphothreonine-containing peptides during CID-MS/MS. A: Charge-remote $\beta$-elimination mechanism, (B) charge-directed intramolecular E2 mechanism, and (C) chargedirected intramolecular $\mathrm{S}_{\mathrm{N}} 2$ mechanism, where $\mathrm{R}=\mathrm{H}$ and $\mathrm{CH}_{3}$ for $\mathrm{pS}$ and $\mathrm{pT}$, respectively.

bonding interactions with the phosphate group to facilitate the two charge-directed mechanisms, i.e., that mobile protons are not involved even though the charges are, as shown in Scheme 3 (Palumbo, Tepe, \& Reid, 2008). Importantly, such strong noncovalent gas phase interactions between the phosphate group of phosphorylated serine, threonine, and tyrosine residues and the side-chains of lysine and arginine (as well as quaternary amines) have been previously recognized (Moyer, Cotter, \& Woods, 2002; Woods, 2004; Jackson et al., 2006). In particular, Jackson et al. (2006) have shown that gas phase noncovalent complexes consisting of phosphopeptides and highly basic peptides are stabilized from dissociation upon CID by these interactions.

(1) Competing phosphate fragmentation pathways: combined losses

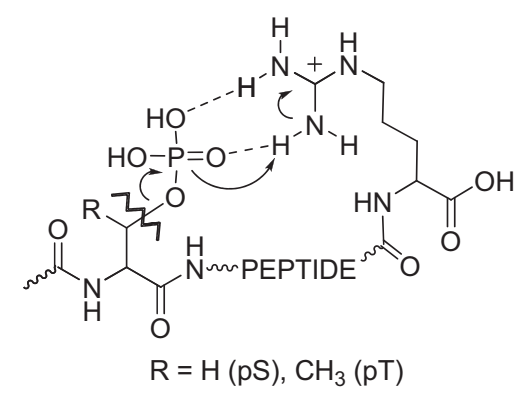

SCHEME 3. Hydrogen bonding interactions between a phosphate group and the guanidinium cationic side chain of arginine, facilitating the charge-directed neutral loss of $\mathrm{H}_{3} \mathrm{PO}_{4}$, where $\mathrm{R}=\mathrm{H}$ and $\mathrm{CH}_{3}$ for $\mathrm{pS}$ and $\mathrm{pT}$, respectively.
Phosphorylated peptides containing multiple potential phosphorylation sites may also give rise to the $98 \mathrm{Da}$ neutral loss product ion by the combined losses of $\mathrm{HPO}_{3}$ and $\mathrm{H}_{2} \mathrm{O}$ (80 and $18 \mathrm{Da}$, respectively) from a phosphorylated residue and a nonphosphorylated hydroxyl (or carboxyl)-containing amino acid residue, respectively (Scheme 4A; Qin \& Chait, 1997; DeGnore \& Qin, 1998). Evidence for the combined losses of $\mathrm{HPO}_{3}$ and $\mathrm{H}_{2} \mathrm{O}$ has been demonstrated by the observation of product ions corresponding to unmodified residues at formerly phosphorylated sites and dehydrated residues at formerly nonphosphorylated sites, following CID-MS ${ }^{3}$ of the initial $98 \mathrm{Da}$ neutral loss product ions observed from synthetic phosphopeptides (Palumbo $\&$ Reid, 2008). Note that this pathway has also been previously used to rationalize the observed neutral loss of $98 \mathrm{Da}$ from phosphotyrosine-containing peptides, since phosphotyrosine may not undergo direct loss of $\mathrm{H}_{3} \mathrm{PO}_{4}$ by the proposed mechanisms shown in Scheme 2 (Qin \& Chait, 1997; DeGnore \& Qin, 1998).

(2) Competing phosphate fragmentation pathways: phosphate group transfer

The neutral loss of $98 \mathrm{Da}$ from phosphotyrosine residues has also been previously rationalized as occurring via initial phosphate group transfer from the phosphotyrosine residue to an unmodified serine or threonine within the peptide, followed by the direct neutral loss of $\mathrm{H}_{3} \mathrm{PO}_{4}$ (DeGnore \& Qin, 1998). In fact, a recent study has demonstrated that such intramolecular gas phase phosphate group transfer can occur for protonated phosphotyrosine-, phosphothreonine-, and phosphoserine-containing peptides (Scheme 4B; Palumbo \& Reid, 2008). An example is shown in Figure 7A and B, which show the product ion spectra obtained by CID-MS/MS of the singly and doubly protonated precursor ions of the synthetic phosphopeptide HEVSASpTQpSTPASSR, where products were observed that unambiguously corresponded to "erroneous" $\mathrm{y}_{5}+\mathrm{HPO}_{3}\left(\mathrm{y}_{5}\right)$ and $\mathrm{y}_{6}+\mathrm{HPO}_{3}\left(\mathrm{y}_{6}\right)$ sequence ions, indicating localization of the phosphate group within the formerly nonphosphorylated $C$-terminal pentapeptide or hexapeptide region of the peptide TPASSR, at approximately $10 \%$ of the abundance of the unmodified "correct" $\mathrm{y}_{5}$ and $\mathrm{y}_{6}$ products (Palumbo \& Reid, 2008). Notably, $45 \%$ of the peptides studied gave rise to such "erroneous" sequence ions. Both mono- and multiply-phosphorylated peptides, as well as phosphorylated serine-, threonine-, and tyrosine-containing peptides, were observed to undergo the phosphate group transfer reaction (Palumbo \& Reid, 2008). It was also determined that the proton mobility of the peptide had significant influence on this reaction (Palumbo \& Reid, 2008). Specifically, the propensity for phosphate group transfer was greatest for peptide precursor ions with either nonmobile or partially mobile protons, similar to that for the neutral loss of $\mathrm{H}_{3} \mathrm{PO}_{4}$ described above. For example, CIDMS/MS of the nonmobile singly protonated precursor ion (panel A) and the partially mobile doubly protonated precursor ion (panel B) of the HEVSASpTQpSTPASSR peptide shown in Figure 7 both gave rise to phosphate group transfer ions $\left(\mathrm{y}_{6}+\mathrm{HPO}_{3}\left(\mathrm{y}_{6}\right)\right.$ and/or $\mathrm{y}_{5}+\mathrm{HPO}_{3}\left(\mathrm{y}_{5}\right)$, respectively), whereas no evidence for rearrangement was observe for the mobile triply protonated precursor ion (panel C; Palumbo \& Reid, 2008).

From this observed relationship between proton mobility and the propensity for phosphate group transfer, it was proposed that the transfer was facilitated by hydrogen bonding interactions between the phosphate group and basic residues (Scheme 4B; 
A

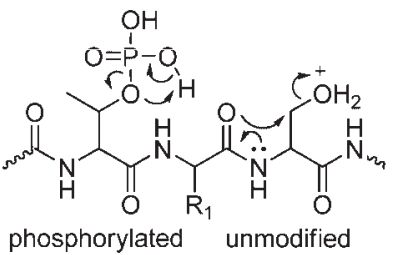

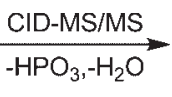<smiles>[R7]C(NC(=O)C(NC(C)=O)C(C)O)C1=NC(C(=O)NC)CO1</smiles>

B

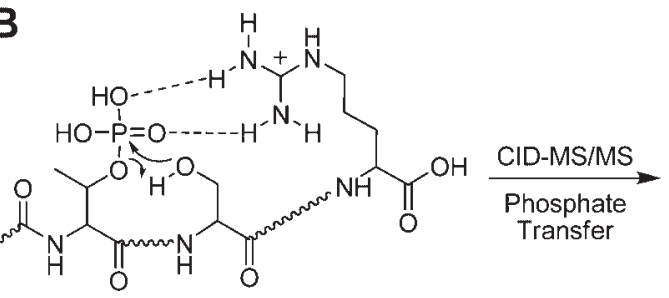

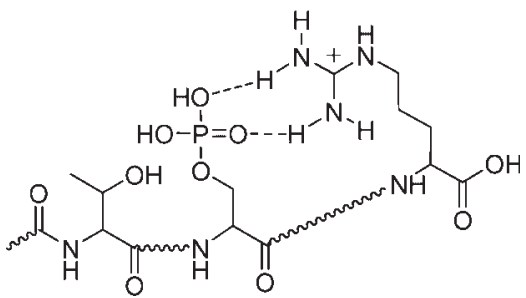

SCHEME 4. Competing phosphate fragmentation mechanisms upon CID-MS ${ }^{n}$. A: Proposed mechanism for the combined neutral losses of $\mathrm{HPO}_{3}$ and $\mathrm{H}_{2} \mathrm{O}(98 \mathrm{Da})$ from a phosphorylated residue and a nonphosphorylated residue, respectively. B: Proposed mechanism for intramolecular phosphate group transfer for protonated peptide ions.

Palumbo \& Reid, 2008). It was also demonstrated that the ion activation timescale influenced the propensity for the phosphate group transfer, whereby short activation times in the microsecond timescale (such as that achieved in the collision cells of triple quadrupole or quadrupole time of flight mass spectrometers) resulted in a lower propensity for transfer than ion activation in the millisecond timescale (such as that typically used in quadrupole ion traps; Palumbo \& Reid, 2008). Analogous intramolecular gas phase phosphate group transfer reactions using alternative ion activation methods, namely PSD, have also been previously proposed (see below).

Intramolecular phosphate group transfer of deprotonated phosphopeptides upon CID-MS/MS has also recently been demonstrated by Lehmann and co-workers, with transfer observed from a phosphotyrosine residue to other amino acids such as those containing hydroxyl or carboxyl functional groups (Scheme 5; Edelson-Averbukh et al., 2009). Although no sequence product ions containing the transferred phosphate were observed, CID-MS/MS of differentially labeled peptides provided results suggestive of phosphate group transfer from phosphotyrosine to carboxyl groups. In particular, fragmentation of the deprotonated phosphopeptides studied commonly gave rise to the neutral loss of $140 \mathrm{Da}$, which was attributed to the concurrent losses of $98 \mathrm{Da}\left(\mathrm{H}_{3} \mathrm{PO}_{4}\right)$ from the transferred phosphate and $42 \mathrm{Da}(\mathrm{HN}=\mathrm{C}=\mathrm{NH})$ from the $C$-terminal arginine residue by the mechanism shown in Scheme 5 (Edelson-
Averbukh et al., 2009). Note that this proposed mechanism involves the removal of one of the oxygen atoms from the $C$-terminal carboxyl as part of the neutral loss of $\mathrm{H}_{3} \mathrm{PO}_{4}$. Therefore, upon CID-MS/MS of an ${ }^{18} \mathrm{O} C$-terminal carboxyl labeled peptide, the neutral loss would be expected to be $142 \mathrm{Da}$ or $\mathrm{H}_{3} \mathrm{P}^{16} \mathrm{O}_{3}{ }^{18} \mathrm{O}(100 \mathrm{Da})$ and $\mathrm{HN}=\mathrm{C}=\mathrm{NH}(42 \mathrm{Da})$. In fact, the neutral loss of $142 \mathrm{Da}$ was observed for a deprotonated phosphotyrosine-containing peptide that was ${ }^{18} \mathrm{O}$ labeled on the $C$-terminal carboxyl upon CID-MS/MS, providing confirmation of the migration of the phosphate group (Edelson-Averbukh et al., 2009).

In addition to intramolecular phosphate group transfer reactions, intermolecular gas phase phosphate group transfer from a phosphorylated peptide to a nonphosphorylated peptide within a gas phase noncovalent complex has also been reported upon CID-MS/MS (Jackson, Wang, \& Woods, 2005; Woods \& Ferre, 2005; Jackson, Moyer, \& Woods, 2008; Woods, Moyer, \& Jackson, 2008). Notably, Woods and co-workers have demonstrated that upon CID-MS/MS, the phosphate-arginine and phosphate-quaternary amine electrostatic interactions in noncovalent heterodimeric complexes exhibit "covalent-like" stability (Jackson, Wang, \& Woods, 2005; Woods \& Ferre, 2005; Jackson, Moyer, \& Woods, 2008; Woods, Moyer, \& Jackson, 2008). As a result, CID-MS/MS can result in removal of the phosphate group from the serine, threonine, or tyrosine residues by scission of the $\mathrm{P}-\mathrm{O}$ phosphoester bond, and the observation of<smiles>CC(=O)N[C@H]1Cc2ccc(cc2)OP(=O)(O)CCCOC(=O)[C@H](CCNC(=N)N)NCCCCCCC1=O</smiles>
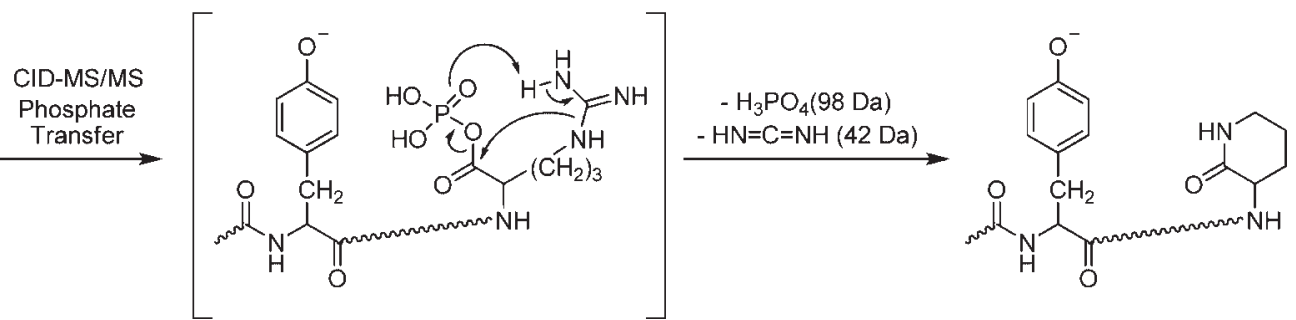

SCHEME 5. Proposed mechanism for intramolecular phosphate group transfer for deprotonated peptide ions. 
a product ion corresponding to retention of the phosphate via a noncovalent interaction to an arginine or quaternary amine within the formerly nonphosphorylated peptide (Jackson, Wang, \& Woods, 2005; Woods \& Ferre, 2005; Jackson, Moyer, \& Woods, 2008; Woods, Moyer, \& Jackson, 2008). Jackson, Moyer, and Woods (2008) have shown that the propensity for noncovalent intermolecular gas phase phosphate group transfer decreases with increasing charge state, similar to that discussed above for the intramolecular gas phase phosphate group transfer reaction of protonated peptides. In view of this apparent gas phase interaction between phosphate moieties and basic residues, it is likely that the mechanism for the neutral loss of $80 \mathrm{Da}$ is also facilitated by these noncovalent hydrogen bonding interactions.

How the chemistry of 80 and 98Da neutral loss product ions affects the applicability of CID phosphoproteome analysis strategies. The observation of dominant nonsequence ions resulting from selective cleavage of the phosphate group upon CID-MS/MS may be both beneficial (i.e., to allow determination of the presence of a phosphopeptide from within a complex mixture) and detrimental (i.e., when they preclude the formation of sequence ions from which information can be obtained for peptide identification and localization of the phosphorylation site). Therefore, with the knowledge of the gas phase chemistry responsible for the formation of these neutral loss product ions, the overall analytical strategy and dissociation method employed for phosphoproteome analysis may be improved or tailored to meet the needs of the experiment. For example, nonsequence product ions derived from phosphate group losses have been widely used as "diagnostic" markers to indicate the presence of phosphorylated peptides in mixtures, thereby enabling the development of "triggered" CID-MS ${ }^{3}$ analyses or MS/MS activation employing alternate dissociation techniques (e.g., ECD; see Fig. 2 arrows connecting MS/MS methods to their respective diagnostic ions and then to other MS/MS or $\mathrm{MS}^{3}$ methods; Chang et al., 2004; Schroeder et al., 2004; Wolschin et al., 2005; Beausoleil et al., 2006; Kocher et al., 2006; Olsen et al., 2006; Sweet, Creese, \& Cooper, 2006; Williamson, Marchese, \& Morrice, 2006; Lee et al., 2007). Since these analysis strategies are highly dependent on formation of the neutral loss product ions as abundant species, the ions subjected to the initial CID-MS/MS step would preferably be those with limited proton mobility (e.g., singly protonated tryptic phosphopeptide ions). Conversely, to decrease the likelihood for observation of selective phosphate group cleavage reactions, such that detailed sequence information for peptide identification and phosphorylation site localization may be directly obtained (either by repeated CID-MS/MS or subsequent ECD-MS/MS), the analysis of precursor ions with increased proton mobility (e.g., highly multiply charged ions) are preferred.

\section{(1) $\mathrm{CID}-\mathrm{MS} / \mathrm{MS}$}

Unfortunately, even when sequence ions are observed, unambiguous phosphorylation site assignment using CID-MS/MS may be complicated by the various fragmentation mechanisms by which the aforementioned phosphate neutral losses are formed. In particular, the presence of sequence ions that have undergone subsequent phosphate neutral loss (e.g., $\mathrm{b}_{n}-80$ or $\mathrm{b}_{n}-98$ ) can complicate phosphate site interpretation since they are isostructural to other nonphosphorylated ions. For example, sequence ions that have also undergone the loss of $\mathrm{H}_{2} \mathrm{O}$ from a nonphosphorylated residue within a particular phosphopeptide isomer may be easily confused with sequence ions that have undergone the loss of $\mathrm{H}_{3} \mathrm{PO}_{4}$ from a phosphorylated residue within a different phosphopeptide isomer of the same peptide. Additionally, sequence ions that have undergone the neutral loss of $\mathrm{HPO}_{3}$ are indistinguishable from nonphosphorylated residues (Palumbo \& Reid, 2008).

Furthermore, the reliability of phosphate-intact sequence ions in CID-MS/MS spectra employed for phosphorylation site localization may also be compromised due to the potential for intramolecular gas phase phosphate group transfer, as described above. In particular, phosphate group transfer is more likely to be observed under collisional activation conditions on the millisecond timescales (Palumbo \& Reid, 2008); hence, phosphorylation site assignments by CID-MS/MS are more likely to be correct using QqQ or qTOF mass spectrometers (microsecond timescale ion activations) rather than on conventionally-operated quadrupole ion traps. As described above however, the likelihood of an incorrect assignment due to phosphate migration following CID-MS/MS can be greatly minimized in ion trap mass spectrometers by selection of an appropriate (i.e., high) precursor ion charge state, since the phosphate group transfer reaction is predominantly observed only under conditions of limited proton mobility (Palumbo \& Reid, 2008).

\section{(2) CID-MS/MS-data dependent methods}

When the formation of $b$ - and y-sequence product ions are suppressed by formation of the dominant $98 \mathrm{Da}$ neutral loss nonsequence product ion, thereby precluding the ability to directly determine the sequence of the phosphopeptide or to localize the site of phosphorylation within the peptide from the CID-MS/MS spectrum, several alternative "data-dependant" acquisition methods have been developed to obtain the required structural information.

One of these methods involves automatically subjecting the initial CID-MS/MS $98 \mathrm{Da}$ neutral loss product ion to either multistage CID-MS/MS (i.e., $\mathrm{MS}^{3}$ ) or "pseudo-MS" ${ }^{3}$ ", (Fig. 2 $\mathrm{MS}^{3}$ methods) in ion trap mass spectrometers in a data dependent mode of operation (Chang et al., 2004; Schroeder et al., 2004; Wolschin et al., 2005; Olsen et al., 2006; Lee et al., 2007). CID$\mathrm{MS}^{3}$ entails isolation and further fragmentation of the neutral loss species, whereas pseudo-MS ${ }^{3}$ involves simultaneous activation of the precursor ion and the resultant $98 \mathrm{Da}$ neutral loss product ion during a single CID-MS/MS event (Schroeder et al., 2004). Therefore, the pseudo-MS ${ }^{3}$ product ion spectrum contains a "composite" of the product ions generated by fragmentation of both the precursor ion and the initial neutral loss product ion. These strategies are, however, highly dependent upon the resultant product ion structure and the mechanism(s) by which it is formed. Although the resultant CID-MS ${ }^{3}$ or "pseudo-MS", product ion spectra may provide additional sequence information for peptide identification, to unambiguously assign the site of phosphorylation by these methods, the product ions formed following CID-MS ${ }^{3}$ or "pseudo-MS ${ }^{3}$ " must reflect the phosphorylation site of the phosphopeptide that was originally introduced to the mass spectrometer. Thus, given the different pathways by which the $98 \mathrm{Da}$ neutral loss product ion may be 
formed (e.g., via the direct loss of $\mathrm{H}_{3} \mathrm{PO}_{4}$ or by the consecutive losses of $\mathrm{HPO}_{3}$ and $\mathrm{H}_{2} \mathrm{O}$ ), as well as due to the potential for intramolecular phosphate group transfer prior to the direct loss of $\mathrm{H}_{3} \mathrm{PO}_{4}$, phosphorylation site assignment by these methods may be ambiguous or erroneous. This rationale is supported by several recent studies that have reported a limited usefulness of CID-MS ${ }^{3}$ for phosphorylation site assignment (Beausoleil et al., 2006; Li et al., 2007).

As an alternative to the use of CID-MS ${ }^{3}$, the observation of 98 Da neutral loss product ions upon CID-MS/MS has also been used to trigger the acquisition of an ECD-MS/MS spectrum on the original precursor ion (Fig. 2 shown with arrow connecting diagnostic ions to ECD MS/MS) in an FT-ICR mass spectrometer, under which conditions the phosphate group remains intact (Sweet, Creese, \& Cooper, 2006; Sweet \& Cooper Helen, 2009). Once again however, as the sensitivity and overall utility of this analysis strategy is highly dependent on the observation of the initial neutral loss product ion as an abundant species, the precursor ions initially subjected to CID-MS/MS would preferably be those with limited proton mobility (e.g., singly protonated tryptic phosphopeptide ions). However, singly charged precursor ions are not amenable to ECD, thereby placing potential limitations on this approach, unless an improved data dependant CID/ECD acquisition strategy could be developed to automatically select a high charge state precursor ion for ECDMS/MS based on the information obtained by initial CID-MS/ MS of low charge state precursor ions.

\section{(3) Chemical derivatization and CID-MS/MS}

To circumvent limitations associated with the lability of the phosphate group upon CID-MS/MS, other phosphopeptide characterization strategies have been developed involving the use of chemical derivatization and conversion of the phosphopeptides, prior to CID-MS/MS. One of the simplest derivatization techniques involves $\beta$-elimination of phosphate groups to form the dehydrated species (dehydroalanine for phosphoserine and dehydroaminobutyric acid for phosphothreonine) under alkaline conditions, followed by Michael addition with a nucleophile to produce a modified amino acid side chain that is stable under CID-MS/MS conditions (Meyer et al., 1986). This method has been adapted such that dithiol nucleophiles may act as crosslinkers between modified peptides and affinity materials such as biotin or solid phase resins allowing for both phosphopeptide enrichment and altered CID gas phase fragmentation behavior (Goshe et al., 2001; Oda, Nagasu, \& Chait, 2001; McLachlin \& Chait, 2003; Thaler et al., 2003). This approach has also been used to transform phosphorylated serine residues to aminoethyl cysteine, a lysine mimic (Knight et al., 2003). By this method, the formerly phosphorylated sites can be targeted for proteolysis by trypsin and the formerly phosphorylated peptides are subsequently identified by sequence analysis of the CID-MS/ MS spectra. Alternatively, other methods have involved conversion of the phosphate group to introduce 2-dimethylaminoethanesulfoxide or $S$-pyridylethyl groups, followed by CID-MS/ MS, giving rise to characteristic protonated dimethylaminoethanesulfenic acid ( $\mathrm{m} / \mathrm{z}$ 122.06; Steen \& Mann, 2002) or protonated vinylpyridine $(\mathrm{m} / \mathrm{z}$ 106; Arrigoni et al., 2006) product ions, respectively. Note however, that the abundance of these characteristic product ions are also dependent upon the proton mobility of the peptide precursor ion and as a result, they may not be universally detected. Furthermore, due to their low $\mathrm{m} / \mathrm{z}$, these methods may not be applicable for detection in ion traps under typical CID conditions. Drawbacks for all of these techniques also exist since (i) $O$-linked sugars and nonphosphorylated serine and threonine residues may also undergo elimination, (ii) phosphotyrosine does not undergo elimination, and (iii) precautions that may be taken to reduce the elimination of nonphosphorylated residues may cause limited conversion efficiency of the phosphorylated residues (McLachlin \& Chait, 2003).

Since the involvement of gas phase interactions between the phosphate groups and side chains of basic residues have been demonstrated to be involved in the phosphorylated side chain cleavage reactions (Jackson, Wang, \& Woods, 2005; Jackson et al., 2006; Palumbo \& Reid, 2008; Palumbo, Tepe, \& Reid, 2008), other derivatization approaches that block these interactions may also be used to decrease the lability of the phosphate group upon CID. Indeed, reaction with malondialdehyde has been used to decrease the basicity of arginine in phosphorylated peptides and CID-MS/MS of these derivatized phosphopeptides resulted in a decrease in the abundance of the $98 \mathrm{Da}$ neutral loss species and a corresponding increase in the phosphatecontaining b- and y-type product ions (Leitner, Foettinger, \& Lindner, 2007). Gronert et al. have also shown that protonated phosphopeptides may react in the gas phase with alkoxy-boron species in an ion-molecule reaction (Gronert, Huang, \& Li, 2004; Gronert, Li, \& Horiuchi, 2005). CID-MS/MS of the resulting $[M+\mathrm{B}-\mathrm{H}]^{+}$derivatized peptide ions results in phosphopeptide backbone fragmentation and inhibits the loss of $\mathrm{H}_{3} \mathrm{PO}_{4}$, thereby decreasing the ambiguity of phosphorylation site assignment by CID.

d. Product ions formed via selective backbone cleavage adjacent to the phosphorylated amino acid residue. Recently, Gehrig et al. (2009) have reported a significant increase in the abundance of y-type ions resulting from enhanced bond cleavage on the $C$-terminal side of phosphothreonine or phosphoserine in arginine-, and to a lesser extent, lysine-containing phosphopeptides under non-mobile protonation conditions, by using MALDI-CID TOF/TOF and ion trap based ESI-CID MS/ MS. Cleavages at phosphoamino acids were found to be particularly predominant at pSer/pThr-Pro bonds, similar to that previously described for enhanced cleavage $C$-terminal to Asp residues in non-phosphorylated peptides (Kapp et al., 2003).

2. MALDI Post-Source Decay (PSD). Post-source decay (PSD) has also been used for phosphopeptide characterization (Fig. 2(3)). PSD involves the dissociation of a metastable precursor ion in the field free region of a TOF instrument (Kaufmann, Spengler, \& Lutzenkirchen, 1993). Metastable ions are those that are stable enough to exit the MALDI source, but are not stable enough to survive the flight to the detector. The resulting product ions are resolved by their difference in kinetic energy (as a result of their difference in mass) in a reflector TOF (Tang et al., 1988). Ion activation for PSD is thought to originate from different mechanisms, where those of major influence occur in the source via photon-molecule interactions, matrixmolecule interactions, temperature effects, etc. (Spengler, 1997). 
Similar to CID, PSD of peptide ions generally give rise to sequence information as b- and y-type product ions (Rouse, Yu, \& Martin, 1995). For phosphopeptides, sequence ions and nonsequence product ions resulting from the neutral losses of $98 \mathrm{Da}\left(\mathrm{H}_{3} \mathrm{PO}_{4}\right.$ or $\left.\mathrm{HPO}_{3}+\mathrm{H}_{2} \mathrm{O}\right)$ and $80 \mathrm{Da}\left(\mathrm{HPO}_{3}\right)$ are typically observed in positive ion mode (Fig. 2(3b); Annan \& Carr, 1996; Hoffmann et al., 1999; Metzger \& Hoffmann, 2000). The phosphotyrosine-specific immonium ion has also been observed by PSD in positive ion mode (Fig. 2(3a)). For example, Figure 8 shows the PSD spectrum of a singly protonated phosphotyrosine containing peptide TRDIYETDpYYRK. Abundant nonsequence product ions corresponding to the neutral losses of $98 \mathrm{Da}$ (assigned as $M+\mathrm{H}-\mathrm{HPO}_{3}-\mathrm{H}_{2} \mathrm{O}$ ) and $80 \mathrm{Da}$ (assigned as $M+\mathrm{H}-\mathrm{HPO}_{3}$ ) are observed, as well as sequence ions resulting from sequential fragmentation of the phosphate group (e.g., $\mathrm{y}_{4^{-}}$ 80 , labeled as $\mathrm{y}_{4}$ ), and the phosphotyrosine-specific immonium ion at $\mathrm{m} / \mathrm{z} 216$ (labeled as $\mathrm{pY}$ ).

a. PSD gas phase ion chemistry of phosphorylated peptides Similar to CID, the loss of $98 \mathrm{Da}$ is more prevalent following the PSD of phosphoserine- and phosphothreonine-containing peptides than phosphotyrosine-containing peptides (Annan \& Carr, 1996). It has also been determined that the loss of $80 \mathrm{Da}$ occurs more readily for phosphorylated tyrosinecontaining peptides than for those containing phosphoserine or phosphothreonine (Annan \& Carr, 1996). Furthermore, the ratio of the relative abundance of phosphate-intact sequence ions versus their "dephosphorylated" counterparts (e.g., $b_{n}-80$ and $\left.b_{n}-98\right)$ is high for phosphotyrosine-containing peptides and varies for phosphoserine- and phosphothreonine-containing peptides (Annan \& Carr, 1996; Hoffmann et al., 1999; Metzger \& Hoffmann, 2000). This is exemplified for the phosphotyrosinecontaining peptide in Figure 8, where most of the sequence product ions are found to retain the phosphate, whereas the $\mathrm{y}_{4}-80$ ion is the only dephosphorylated sequence ion observed.

Due to the similarities in CID and PSD product ion spectra, it is likely that the mechanisms by which the phosphate neutral loss product ions are formed are similar. Accordingly, it has been previously hypothesized that the neutral loss of 98 Da upon PSD of phosphorylated serine- and threonine-containing peptides may result from the direct loss of $\mathrm{H}_{3} \mathrm{PO}_{4}(98 \mathrm{Da})$ or from the consecutive losses of $\mathrm{HPO}_{3}$ from a phosphorylated residue and $\mathrm{H}_{2} \mathrm{O}$ from a nonphosphorylated residue (with a combined loss of 98 Da; Annan \& Carr, 1996; Schnolzer \& Lehmann, 1997). As a result, the observed neutral losses of $98 \mathrm{Da}$ from phosphotyrosine-containing peptides upon PSD (as shown in Fig. 8) have been assigned as being due to the combined neutral losses of $\mathrm{HPO}_{3}$ and $\mathrm{H}_{2} \mathrm{O}$ (Annan \& Carr, 1996). Additionally, the possibility of intramolecular phosphate group transfer from a phosphorylated tyrosine to a formerly unmodified residue, followed by loss of $\mathrm{H}_{3} \mathrm{PO}_{4}$, has also been proposed previously for PSD (Metzger \& Hoffmann, 2000). In that study, it was demonstrated that the neutral loss of $\mathrm{H}_{3} \mathrm{PO}_{4}$ depended on the presence of aspartic acid and arginine residues. By this observation it was proposed that the $\mathrm{HPO}_{3}$ group was transferred from tyrosine to aspartic acid followed by cleavage, forming a succinamide (Metzger \& Hoffmann, 2000).

b. PSD analysis strategies and how they are impacted by the chemistry. The use of phosphate neutral loss nonsequence product ions in PSD spectra as diagnostic indicators of the presence of phosphopeptides has previously been proposed (Annan \& Carr, 1996). Like CID, the overall utility and sensitivity of these methods are dependent on the ability to observe these ions as abundant species. Phosphopeptide identification and phosphorylation site localization by PSD also bears similar attributes to CID. For example, it has been previously noted that $b$ - or y-type product ions that undergo the subsequent loss of $\mathrm{HPO}_{3}$ may easily be confused with nonphosphorylated residues, and that $\mathrm{b}$ - or $\mathrm{y}$-type product ions that undergo the subsequent loss of $\mathrm{H}_{3} \mathrm{PO}_{4}$ are isostructural with dehydrated serine and threonine residues, thereby complicating phosphorylation site assignment (Annan \& Carr, 1996). Additionally, the possibility of consecutive losses of $\mathrm{HPO}_{3}$ and $\mathrm{H}_{2} \mathrm{O}$, or for phosphate group transfer, impose the same ambiguities regarding phosphorylation site localization by PSD as for CID.

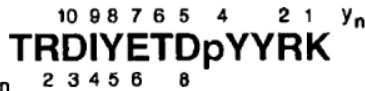

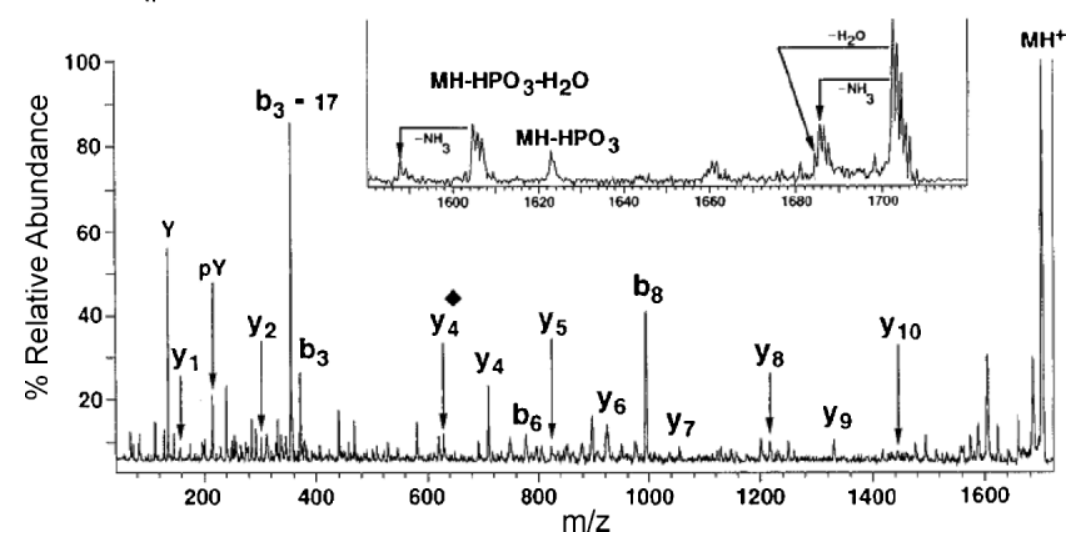

FIGURE 8. Reflectron-TOF PSD product ion spectrum of the singly protonated peptide TRDIYETDpYYRK, where $\diamond=-80 \mathrm{Da}\left(\mathrm{HPO}_{3}\right)$; $\mathrm{Y}=$ tyrosine immonium ion; $\mathrm{pY}=$ phosphotyrosine immonium ion. Reproduced from Annan and Carr (1996) with permission from American Chemical Society, copyright 1996. 
3. Photodissociation. Ions in the gas-phase may be excited and subsequently dissociated by absorption of photons. Photodissociation (PD) techniques may be relatively selective in comparison to the aforementioned techniques, as only ions that absorb the wavelength of the light used are activated. These techniques are most often used with ion trapping mass spectrometers, because they allow for ions to be confined to the area irradiated by the light.

a. Infrared multiple-photon dissociation (IRMPD). Ion activation may be achieved using infrared lasers (Brodbelt \& Wilson, 2009; Eyler, 2009). Due to its relatively low energy ( $\sim 0.1 \mathrm{eV} /$ photon), the absorption of multiple IR photons (tens to hundreds) are required for ion dissociation. Ions are typically irradiated for tens to hundreds of milliseconds for a continuous-wave $\mathrm{CO}_{2}$ $(10.6 \mu \mathrm{m})$ laser. Like CID, IRMPD is a "slow heating" method and allows for intramolecular energy redistribution over all of the vibrational degrees of freedom prior to the next photon absorption event (McLuckey \& Goeringer, 1997). As a result, ergodic dissociation of low-energy pathways predominates and the resulting spectra are generally comparable with those obtained by CID.

Since the $\mathrm{P}-\mathrm{O}$ stretch $(9.6-11 \mu \mathrm{m})$ is in resonance with $10.6 \mu \mathrm{m}$ light, the phosphate groups of phosphorylated peptides provide strong chromophores for efficient dissociation by IRMPD (Little et al., 1994; Flora \& Muddiman, 2004); hence, IRMPD has been used for phosphopeptide characterization (Fig. 2(4)). A representative IRMPD spectrum acquired in an ion trap for a doubly protonated phosphotyrosine containing peptide TRDIYETDYpYRK, is shown in Figure 9A. For comparison, the CID-MS/MS spectrum of the same peptide is also shown (Fig. 9B). It can be seen that the types and abundances of the various product ions, including those corresponding to the dominant nonsequence neutral loss of $98 \mathrm{Da}$ from the precursor ion and sequence ions resulting from sequential neutral loss of the phosphate group, and the overall sequence coverage, are similar for both IRMPD and CID spectra (Crowe \& Brodbelt, 2004). However, as IRPMD can be performed relatively independently of the low mass cutoff that is inherent to CID in the ion trap, more product ions are observed in the low $\mathrm{m} / \mathrm{z}$, region for the IRMPD spectrum than that from CID.

Although the selective detection of phosphorylated peptides from mixtures by using IRMPD has been achieved via the observation of characteristic 80 and $98 \mathrm{Da}$ neutral loss species (Fig. 2(4b); Flora \& Muddiman, 2001, 2002; Chalmers et al., 2003; Crowe \& Brodbelt, 2004), the same complications for phosphopeptide sequencing and phosphorylation site characterization that were discussed above for CID and PSD are also present for IRMPD.

b. Ultraviolet photodissociation (UVPD). Photodissociation in the UV range has targeted common chromophores such as the amide bonds of a peptide using 193 and $157 \mathrm{~nm}$ light, as well as residue-specific chromophores such as aromatic amino acids using 220, 266, and $280 \mathrm{~nm}$ light (Reilly, 2009). Phosphopeptide analysis using UVPD has been performed using $157 \mathrm{~nm}$ (Kim \& Reilly), 193 nm (Shin, Moon, \& Kim, 2010), 220 nm (Lemoine et al., 2006), and $266 \mathrm{~nm}$ (after derivatization with a chromophore; Diedrich \& Julian, 2008) light (Fig. 2(5)).

\section{A}
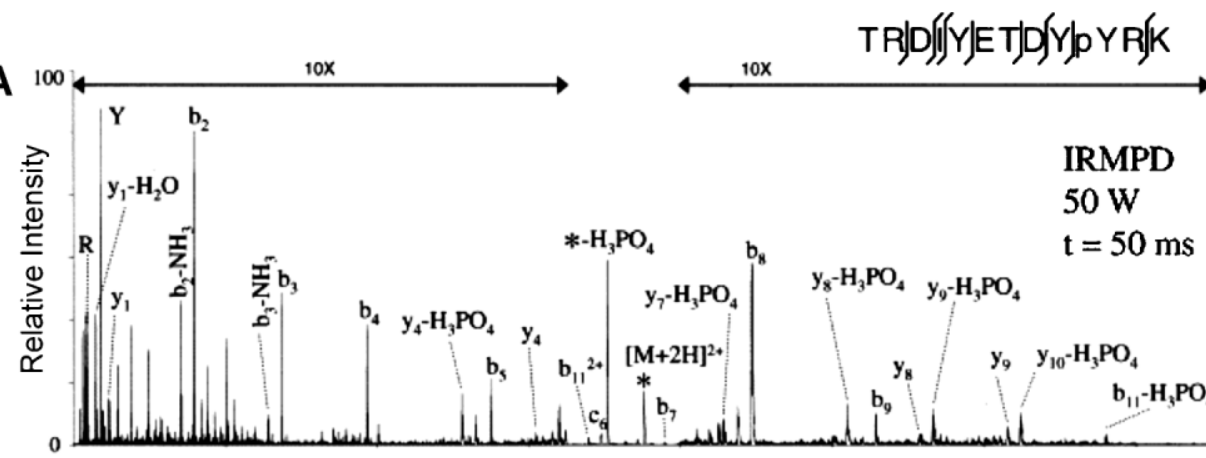
One study by Lemoine et al. (2006) demonstrated that $220 \mathrm{~nm}$ UVPD of peptides containing unmodified tyrosine (as the chromophore) and phosphorylated serine residues $(5.64 \mathrm{eV} /$ photon) results in predominant homolytic cleavage of the tyrosine side chains, with loss of the phosphate group greatly minimized. The formation of the radical product ion at this wavelength was to an extent expected since nonphosphorylated tyrosine-containing peptides have also been shown to give rise to similar cleavages (Tabarin et al., 2005). Similarly, Kim and Reilly (2009) have recently shown that UVPD of singly protonated phosphoserine- and phosphothreonine-containing peptide ions at $157 \mathrm{~nm}(7.90 \mathrm{eV} /$ photon) results in predominant formation of the neutral loss of $98 \mathrm{Da}$ from the precursor ion, whereas phosphotyrosine-containing peptides largely retain the phosphate group. Interestingly, time-resolved detection of the UVPD product ions demonstrated that the nonsequence product ion resulting from the neutral loss of $98 \mathrm{Da}$ from the precursor ion was formed at considerable abundances within $300 \mathrm{~ns}$ (the measurable limit) post-photoexcitation, whereas product sequence ions ( $\mathrm{a}-, \mathrm{b}-, \mathrm{x}-, \mathrm{y}-$, and $\mathrm{z}$-ions) were found to largely retain the phosphate group for up to $1 \mu \mathrm{sec}$ postphotoexcitation (Kim \& Reilly, 2009). These results further demonstrate the lability of the phosphoester bond upon dissociation and its timescale dependence for the formation of nonsequence and sequence product ions. Additionally, a complete series of phosphate-intact sequence ions were observed for all of the model phosphopeptides analyzed by this method (Kim \& Reilly, 2009). Collectively, these observations demonstrate the potential of this strategy for phosphoproteome analysis, since the observed $98 \mathrm{Da}$ neutral loss nonsequence product ion may be used as a diagnostic indicator for the presence of phosphorylated peptides, whereas the complete series of sequence ions with intact phosphate groups allows for unambiguous phosphorylation site assignment.

Diedrich and Julian (2008) have developed an alternative UVPD approach, involving conversion of the phosphate group by $\beta$-elimination of the phosphate group followed by introduction of a UV-absorbing sulfhydryl-containing napthyl chromophore by Michael addition prior to dissociation (Fig. 10A). Upon UVPD at $266 \mathrm{~nm}$ of singly deprotonated or multiply protonated ions, the chromophore allows for enhanced absorbance of the formerly phosphorylated peptides. Furthermore, the carbon sulfur bond connecting the label to the peptide is susceptible to homolytic cleavage of this bond and subsequent loss of the napthylsulfide radical, upon photodissociation (Fig. 10A, also see Fig. 10B where the resultant product ion is labeled with a $\$$; Diedrich \& Julian, 2008). This ion could be used as a diagnostic indicator of the presence of phosphopeptides. Interestingly the only sequence ions observed in the product ion spectrum were those resulting from consecutive cleavage of the napthylsulfide radical and the

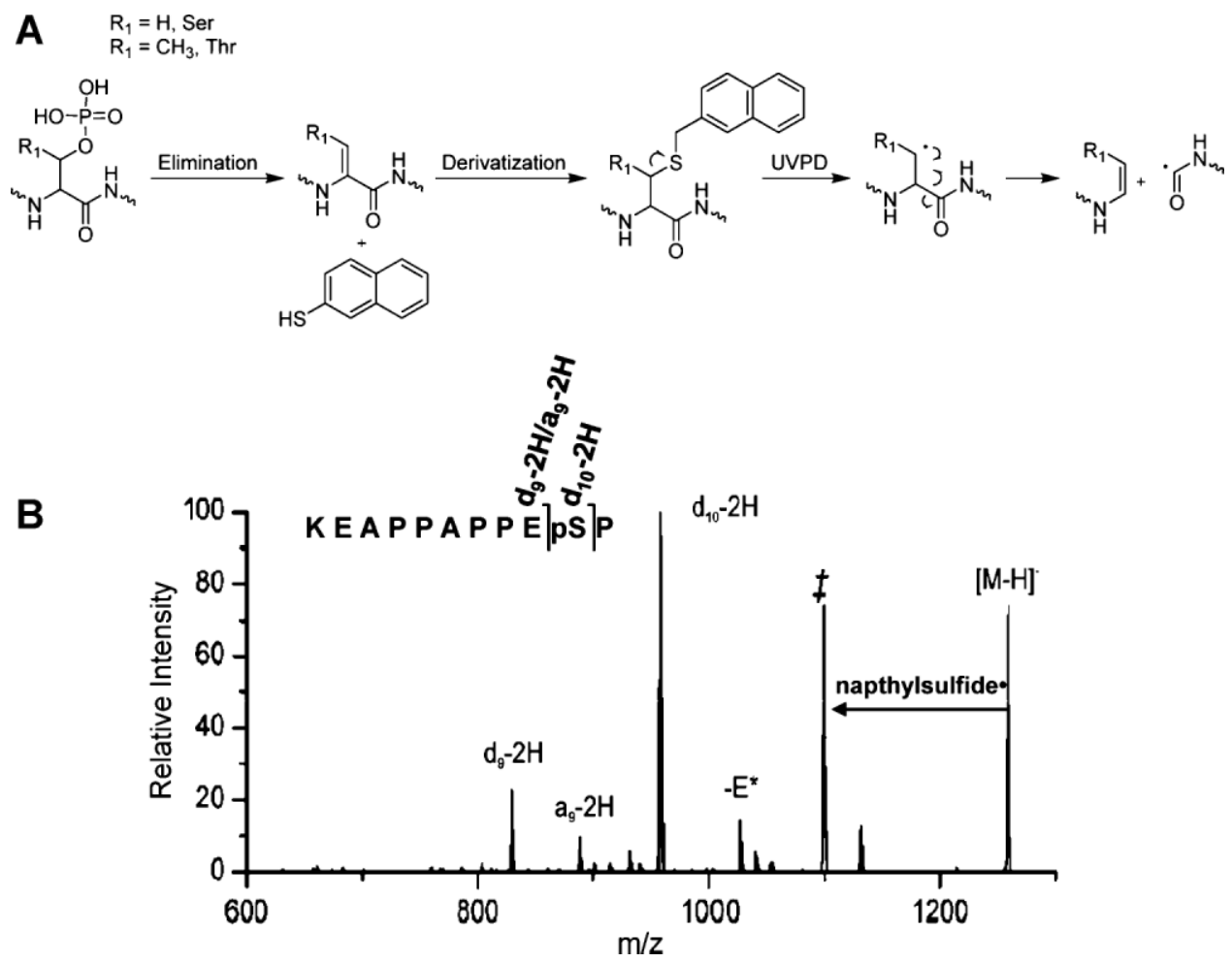

FIGURE 10. Analysis of napthyl chromophore-derivatized phosphorylated serine and threonine peptides by UVPD at $266 \mathrm{~nm}$ in an ion trap. A: Analysis strategy beginning with $\beta$-elimination of phosphoserine and phosphothreonine peptides followed by Michael addition to form the napthyl-derivatized labeled peptides. UVPD of the derivatized peptides results in selective cleavage of the chromophore and radical-induced cleavage allows for the selective formation of sequence ions adjacent to the formerly phosphorylated residue. B: UVPD-MS/MS product ion spectrum of the singly deprotonated peptide KEAPPAPPEpSP. $t=$ loss of napthylsulfide and $-E^{*}=$ loss of glutamic acid side chain. Reproduced from Diedrich and Julian (2008) with permission from American Chemical Society, copyright 2008. 
peptide backbone adjacent to the former position of the label (see Fig. 10B, the singly deprotonated peptide KEAPPAPPEpSP modified at the serine residue gave rise to the loss of napthylsulfide ( $\$$ ) and the $\mathrm{d}_{9}-2 \mathrm{H}, \mathrm{a}_{9}-2 \mathrm{H}$, and $\mathrm{d}_{10}-2 \mathrm{H}$ sequence ions; Diedrich \& Julian, 2008). The production of these sitespecific sequence ions were proposed to occur by the mechanism shown in Figure 10A, where the radical in the $\beta$-position (postnapthylsulfide cleavage) induces adjacent backbone fragmentation (Diedrich \& Julian, 2008). Such site-specific sequence ions could allow for unambiguous assignment of the phosphorylation site within a grouping of potential phosphorylation sites. Although this method would incur the drawbacks of other $\beta$-elimination strategies, the possibility for enhanced absorption, selective fragmentation and the production of characteristic site specific product ions makes it an attractive method for phosphopeptide characterization.

Site-specific dissociation of non-derivatized phosphopeptides at the site of the phosphorylated residue(s) has also been recently demonstrated by Shin, Moon, and Kim (2010), by using UVPD at $193 \mathrm{~nm}$. In that study, phosphorylated peptides containing a basic residue (arginine, lysine, and histidine) at the $\mathrm{N}$-terminus of the peptide resulted in the selective formation of intense $\mathrm{a}_{n}+1-98$ ions solely at phosphorylated residues. An example is shown in Figure 11, where dissociation of the singly protonated triply phosphorylated peptide RLpTpSTpSSF resulted in the formation of $\mathrm{a}_{3}+1-98, \mathrm{a}_{4}+1-98$, and $\mathrm{a}_{6}+1-98$ ions (labeled as $\mathrm{a}_{n}+1-\mathrm{H}_{3} \mathrm{PO}_{4}$ ) resulting from phosphorylation site-specific dissociation. Note that $\mathrm{a}_{5}+1-98$ and $\mathrm{a}_{7}+1-98$ ions are not observed in the spectrum. UVPD of the analogous hydrogen-deuterium exchanged phosphopeptide (H/D exchange completed in solution) demonstrated that the $\mathrm{a}_{n}+1-98$ ions were formed via $\mathrm{H}_{3} \mathrm{PO}_{4}$ loss from the $\mathrm{a}_{n}+1$ radical cation $\left(\mathrm{a}_{n}+1 \rightarrow \mathrm{a}_{n}+1-\mathrm{D}_{3} \mathrm{PO}_{4}, 101 \mathrm{Da}\right.$; Shin, Moon, \& Kim, 2010). Importantly, since these ions form selectively at the phosphorylation sites, they could be used to localize the phosphorylation sites of peptides with multiple serine, threonine, and tyrosine residues.

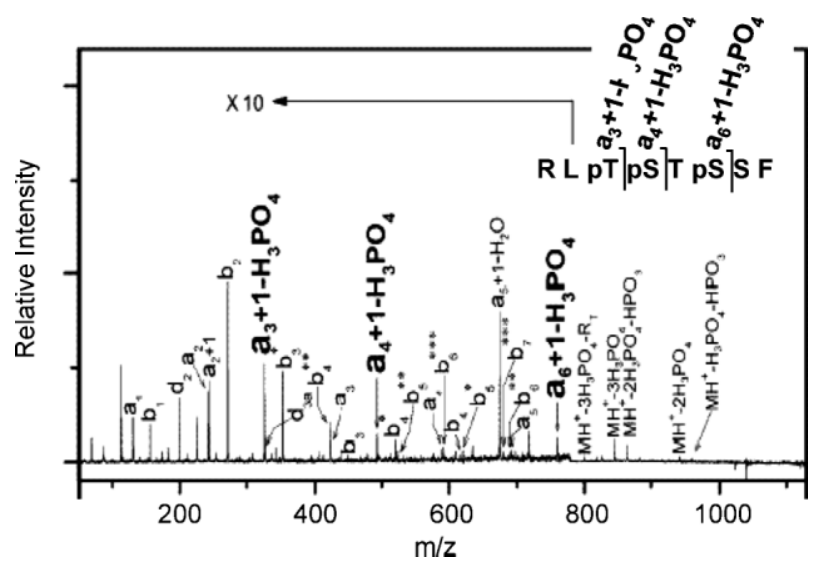

FIGURE 11. $193 \mathrm{~nm}$ UVPD-MS/MS product ion spectrum (subtracted from a laser-on spectrum) of the singly protonated, triply phosphorylated peptide RLpTpSTpSSF collected on a TOF/TOF. Phosphorylated residue-specific cleavage ions are observed resulting from phosphate loss in the form of $\mathrm{H}_{3} \mathrm{PO}_{4}$ from $\mathrm{a}_{n}+1$ radical ions. Reproduced from Shin, Moon, and Kim (2010) with permission from Elsevier, copyright 2010. c. Femtosecond laser-induced ionization/dissociation (fsLID) A new photodissociation technique which has been recently applied to the analysis of phosphopeptides is fsLID (Fig. 2(6); Kalcic et al., 2009). In fsLID, the photons of a near-IR laser ( $\lambda=798 \pm 30 \mathrm{~nm}, \sim 1.55 \mathrm{eV} /$ photon) are concentrated into ultrashort pulses $(\sim 35 \mathrm{fsec})$ to enable very high photon intensities $\left(\sim 10^{14} \mathrm{~W} / \mathrm{cm}^{2}\right)$ for ion activation. With such a high-power femtosecond laser, novel activation processes may be accessible by fsLID. Additionally, since fsLID is capable of satisfying the threshold energy for ion oxidation (electron removal) on a timescale similar to or faster than that of bond vibrations (commonly 10-100 fsec; Zewail, 2000), it is hypothesized that dissociation can occur via non-ergodic pathways, enabling nonselective fragmentation and retention of labile functionalities, such as phosphate groups.

Kalcic et al. (2009) have shown that fsLID-MS/MS of singly and multiply protonated phosphorylated peptides (and nonmodified tryptic peptides) in a modified QIT results in the formation of numerous sequence product ions, including those of the a-, b-, c-, $\mathrm{x}-, \mathrm{y}-$, and z-type. It was determined, by using $\mathrm{MS}^{3}$, that many of these sequence ions were formed as a result of radical-driven dissociation of the photo-oxidized precursor (Kalcic et al., 2009). Importantly, this study showed that fsLIDMS/MS analysis of phosphorylated peptides produces sufficient sequence information to unambiguously identify phosphorylation sites, despite the relatively low fragmentation efficiency in the first generation embodiment of this instrumentation. Additionally, there was no evidence for phosphate group transfer upon fsLID-MS/MS of a phosphopeptide that had previously been shown to readily undergo the transfer reactions under CID-MS/ MS conditions (Kalcic et al., 2009).

An example fsLID spectrum of the singly protonated phosphoserine containing peptide LNQSpSPDNVTDTK is shown in Figure 12A. In this spectrum, a photo-oxidized product $\left([M+\mathrm{H}]^{2+\cdot}\right)$, and numerous a-, b-, c-, and $\mathrm{x}$-type sequence ions providing complete sequence coverage, are observed. Importantly, in contrast to the spectrum obtained by CID-MS/

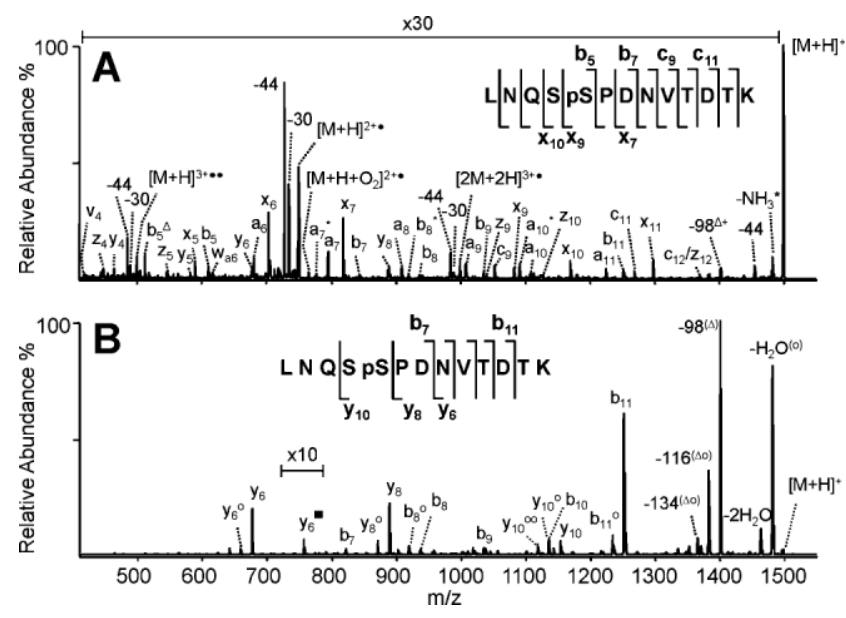

FIGURE 12. Product ion spectra of the singly protonated precursor ion of the synthetic "tryptic" peptide LNQSpSPDNVTDTK obtained by (A) Ion trap fsLID-MS/MS and (B) CID-MS/MS. $\Delta=-98 \mathrm{Da}\left(-\mathrm{H}_{3} \mathrm{PO}_{4}\right.$ or $\left.\left(\mathrm{HPO}_{3}+\mathrm{H}_{2} \mathrm{O}\right)\right) ; \mathrm{O}=-18 \mathrm{Da}\left(-\mathrm{H}_{2} \mathrm{O}\right) ; *=-17 \mathrm{Da}\left(\mathrm{NH}_{3}\right)$; $\mathbf{\square}=+80 \mathrm{Da}\left(+\mathrm{HPO}_{3}\right)$. 
MS of the same peptide (Fig. 12B), the sequence product ions observed by fsLID were all found to retain the phosphate group in the correct location (i.e., no evidence for phosphate group transfer) and therefore enabled unambiguous phosphorylation site determination.

Although the mechanisms associated with both ionization and dissociation have yet to be elucidated, plausible ionization mechanisms for fsLID include multi-photon ionization (MPI) and field ionization. Due to the time scale for energy deposition, the MPI process could occur on so short a timescale as to be nonergodic, allowing for labile groups to be conserved. Also, given the high power at its focus, fsLID might also be capable of ionizing species through field ionization, which could occur if the electric field produced by the photon packet warps ion potential energy surfaces to an extent that the ions may incur the loss of an electron.

4. Electron-Driven Dissociation Methods. Tandem mass spectrometry methods that involve dissociation by electron-ion reactions (ECD, EDD) or ion-ion reactions (ETD) as the "activation" component of the MS/MS experiment have also been used for phosphoproteomic analyses. These techniques have been shown to largely maintain the phosphate group upon dissociation of the precursor ions and therefore overcome the potential problems associated with CID, PSD, and IRMPD. However, as these techniques all involve charge state reduction by the addition or loss of an electron, these approaches are limited to the analysis of multiply charged precursor ions.

a. Electron capture dissociation (ECD). Electron capture dissociation (ECD) involves exothermic capture of a low energy electron $(<0.2 \mathrm{eV})$ by a multiply positively charged species followed by dissociation of the resultant odd electron ion (Zubarev, Kelleher, \& McLafferty, 1998). Since the electron capture process requires low energy electrons $(<10 \mathrm{eV})$ and long interaction times, the application of ECD was traditionally confined to instruments that employ static electromagnetic fields that avoid energizing or heating electrons, such as FTICRs. Recently however, the addition of magnetic fields to ion traps have allowed for ECD in such electrodynamic trapping instruments (Baba et al., 2004; Silivra et al., 2005; Satake et al., 2007) and the use of ECD in a digital ion trap mass spectrometer has also been reported (Ding \& Brancia, 2006).

Protonated precursor ions with $z \geq 2$ are required for ECD-MS/MS because charge reduction of a singly protonated precursor ion would result in an undetectable neutral species. Furthermore, multiply protonated precursor ions formed by ESI are favored for ECD since the electron capture cross section is proportional to the square of the ion charge (Zubarev et al., 2000). Additionally, there have been reports of limited dissociation of doubly protonated precursor ions despite the expected high efficiency of electron capture (Chalmers et al., 2004; Kweon \& Hakansson, 2008). This has been rationalized as being due to the potential for noncovalent interactions (e.g., salt bridges) that prevent the separation of the product ion pairs within the charge reduced product that are formed following the ECD reaction (Chalmers et al., 2004). To overcome such noncovalent interactions and increase the extent of dissociation, McLafferty and co-workers have introduced activated ion-ECD (AI-ECD) which involves ion heating before, during, or after the ECD process (Horn, Ge, \& McLafferty, 2000a). Additionally, supplemental activation of the newly formed charge-reduced precursor ion by using CID may be performed simultaneous to the ECD experiment in ion traps (termed ECD + CID) allowing for increased fragmentation efficiency and reduction of the multiple electron capturing events that otherwise may be observed while performing ECD in a linear ion trap (Bushey, Baba, \& Glish, 2009).

The mechanism for bond dissociation by ECD is dictated by radical reaction chemistry, and for peptides this largely results in the formation of $\mathrm{c}$ - and $\mathrm{z}$-type product ions. A mechanism for the $\mathrm{N}-\mathrm{C}_{\alpha}$ cleavage has been previously proposed and is shown in Scheme 6 (McLafferty et al., 2001), where a $\mathrm{H}^{\cdot}$ produced at the site of the initial electron capture is transferred to a backbone carbonyl group followed by cleavage to form c- and z-ions. However, other proposed mechanisms for $\mathrm{N}-\mathrm{C}_{\alpha}$ cleavage have also been proposed, including direct dissociation upon electron capture at the bond, or $\mathrm{H}^{*}$ capture by the nitrogen atom (Zubarev et al., 2002). Importantly, ECD occurs in a faster timescale than internal energy distribution $\left(\leq 10^{-12} \mathrm{sec}\right)$. Therefore, nonselective fragmentation is achieved rather than kinetically controlled fragmentation (as observed in CID, PSD, and IRMPD). For this reason, ECD of multiply protonated phosphopeptide ions results in retention of the phosphate group upon fragmentation (Stensballe et al., 2000; Shi et al., 2001). As a result, ECD-MS/MS has been used for phosphopeptide identification and unambiguous phosphorylation site assignment (Fig. 2(7); Sweet et al., 2008, 2009). The effectiveness of deriving phosphorylation sites from ECD-MS/MS spectra is demonstrated in Figure 13, which shows an ECD-MS/MS spectrum of two HPLC-co-eluting tryptic phosphopeptide isoforms of LLGSSFSSGPVADGIIR from human Sprouty 2, isolated from human kidney cells (Sweet et al., 2008). In this spectrum, almost complete sequence coverage is observed, readily allowing for peptide identification. In fact, the only c- and z-ions absent relate to cleavage $N$-terminal to proline, which are rarely observed since this would require cleavage through the ring (Cooper et al., 2003). Phosphorylation site identification for these peptides is easily achieved, using the series of adjacent $\mathrm{z}_{12}$, $\mathrm{z}_{13}$, and $\mathrm{z}_{14}$ ions. The presence of two $\mathrm{z}_{13}$ ions, one containing a phosphate group (labeled $\mathrm{z}_{13}$ ) and one unmodified (labeled $\mathrm{z}_{13}{ }^{*}$ ),

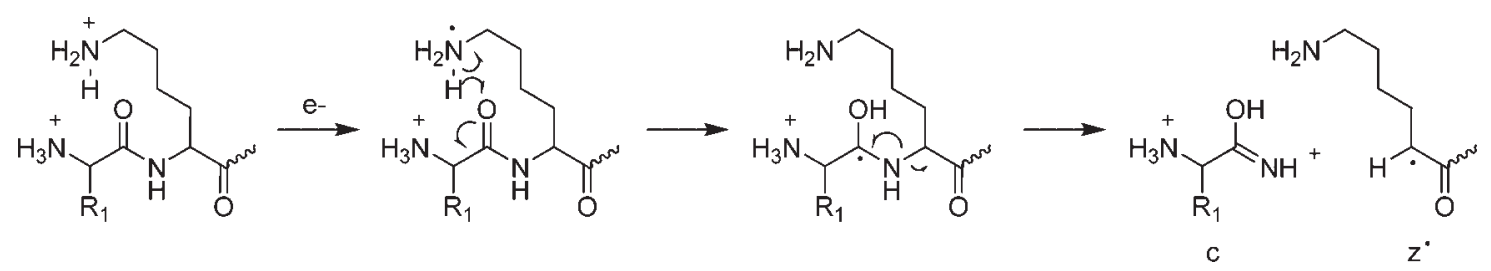

SCHEME 6. Previously proposed fragmentation mechanism for the production of c- and z-type product sequence ions for the reaction between a low-energy electron with a multiply protonated peptide ion. 


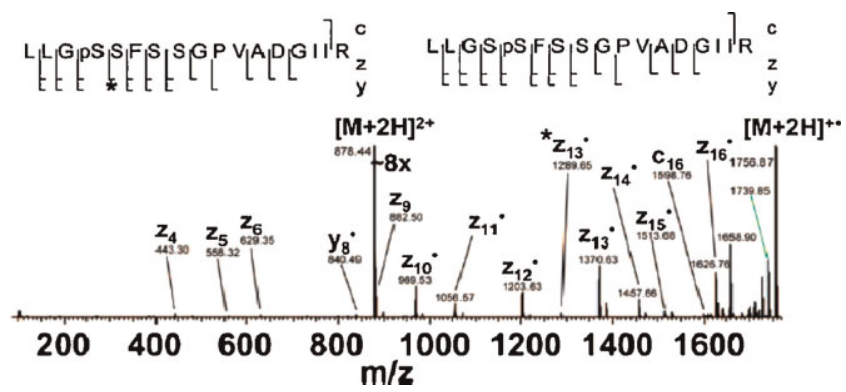

FIGURE 13. FTICR ECD-MS/MS product ion spectrum of HPLC-coeluting doubly protonated precursor ions of LLGpSSFSGPVADGIIR and LLGSpSFSGPVADGIIR phosphopeptide from human Sprouty 2, a regulator of receptor tyrosine kinase signaling. The two isoforms were determined from the presence of the phosphate lacking $\mathrm{z}_{13} *$ and phosphate containing $\mathrm{z}_{13}$ product ions. " $\mathrm{z}_{n} \bullet$ " represents product ions formed by an ECD mechanism such as that shown in Scheme 6 . Reproduced from Sweet et al. (2008) with permission from American Chemical Society, copyright 2008.

allow unambiguous localization of the phosphorylation sites for the two phosphorylated isoforms LLGpSSFSSGPVADGIIR and LLGSpSFSSGPVADGIIR (Sweet et al., 2008). Moreover, although ECD fragment intensities are not necessarily quantitatively indicative of precursor ion abundance, the higher abundance of the $\mathrm{z}_{13}$ ion containing the phosphate group compared to that of the unmodified $\mathrm{z}_{13}$ ion suggests that the LLGpSSFSSGPVADGIIR is the more abundant isoform (Sweet et al., 2008).

Since the phosphate group is maintained by ECD and is generally lost by CID, Cooper and co-workers have proposed and demonstrated the combined utility of these processes through automatic triggering of an ECD-MS/MS spectrum of a protonated precursor ion following an initial observation of the neutral loss of $98 \mathrm{Da}$ by CID (Fig. 2(2) resulting in 2b and subsequent triggering of 7; Sweet, Creese, \& Cooper, 2006; Sweet et al., 2009). However, as noted earlier, the overall sensitivity of this method is dependent on the abundant formation of the phosphate neutral loss product ion by CID to initiate the triggering event (Sweet et al., 2009). Therefore, considering that the neutral loss of $98 \mathrm{Da}$ upon CID-MS/MS is predominantly observed for peptide precursor ions with low proton mobility (low charge state relative to the number of basic residues; DeGnore \& Qin, 1998; Tholey, Reed, \& Lehmann, 1999; Palumbo, Tepe, \& Reid, 2008; Villen, Beausoleil, \& Gygi, 2008), this technique is best suited for the analysis of doubly protonated, phosphorylated serine or phosphorylated threonine peptides. Accordingly, Sweet et al. have shown in a recent large-scale phosphoproteome study that ECD triggering was unsuccessful when the neutral loss was not dominantly observed, for tyrosine-phosphorylated peptides, and when the neutral loss peak was outside the five most intense peaks observed in the CID spectrum (Sweet et al., 2009).

b. Electron transfer dissociation (ETD). Electron transfer dissociation (ETD) is similar to ECD in that it also induces relatively non-selective cleavage of the $\mathrm{N}-\mathrm{C}_{\alpha}$ bond on a peptide's backbone producing c- and z-product ions, while maintaining phosphate groups and other potentially labile modifications (Syka et al., 2004). However, rather than involving the direct capture of an electron, ETD involves transfer of an electron to the multiply protonated precursor ion from a singly charged radical anion. The use of electron donors makes ETD amenable for use in quadrupole ion trap mass spectrometers which utilize rf fields for simultaneous storage and reaction of ions with positive and negative polarities. Since anthracene, fluoranthene, and azobenzene have relatively low electron affinities $(<60-70 \mathrm{kcal} / \mathrm{mol})$, these reagents have been successfully used as electron donors for ETD (Syka et al., 2004; Gunawardena et al., 2005; Chi et al., 2007; Good et al., 2007). After electron transfer to a protonated peptide, the mechanism for dissociation of the $\mathrm{N}-\mathrm{C}_{\alpha}$ bond is thought to be the same as that for electron capture (Scheme 6; Syka et al., 2004).

ETD has been successfully used for phosphoproteome analysis (Fig. 2(8)), enabling phosphoprotein identification and phosphorylation site localization (Chi et al., 2007; Molina et al., 2007; Swaney et al., 2009; Yang et al., 2009). A representative ETD-MS/MS product ion spectrum of the triply protonated doubly phosphorylated peptide HEVSASpTQpSTPASSR is shown in Figure 14. In addition to formation of abundant nondissociated charge-reduced radical cations $\left([M+3 \mathrm{H}]^{++}\right.$and $\left.[M+3 \mathrm{H}]^{+\cdot *}\right)$, almost complete sequence coverage is attained, readily allowing for sequence identification and phosphorylation site localization. Notably, while the sequence coverage of this peptide by ETD was found to be essentially the same as that for CID (compare Fig. 14 with Fig. 7C), no product ions were observed corresponding to sequential loss of the phosphate group from the sequence product ions, or migration of the phosphate group in the ETD spectrum (note that phosphate group migration was seen in the CID spectrum only for the singly and doubly protonated precursor ions).

The performance factors associated with ETD have been previously discussed by Good et al. (2007). In that study, the most significant factor governing ETD peptide fragmentation efficiency was determined to be the charge density or the charge/residue ratio of the precursor ion, where low charge density gave rise to low fragmentation efficiencies. Accordingly, less than $1 \%$ of unmodified peptides identified by ETD were derived from doubly protonated precursor ions (Good et al., 2007). In another large-scale analysis, Swaney, McAlister, and Coon (2008) similarly demonstrated that ETD is most effective for precursor ions with low $\mathrm{m} / \mathrm{z}$ (high charge density). This apparent trend of decreased ETD fragmentation efficiency for precursor ions with low charge density has been attributed to formation of the non-dissociated (intact) charge-reduced radical cation (e.g., $[M+2 \mathrm{H}]^{2+} \rightarrow[M+2 \mathrm{H}]^{+}$; Good et al., 2007; Swaney et al., 2007). To increase the ETD efficiency of doubly protonated precursor ions and other peptide ions with low charge density, the application of supplemental low-energy

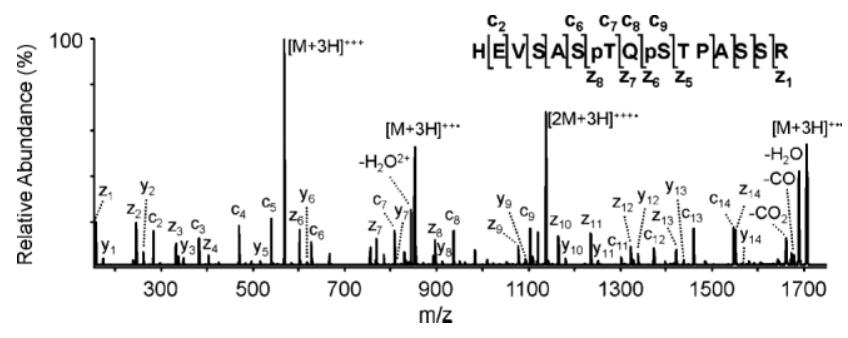

FIGURE 14. Ion trap ETD-MS/MS product ion spectrum of the triply protonated precursor ion of the synthetic peptide HEVSASpTQpSTPASSR. 
collisional activation of these charge reduced radical cations has been employed (Swaney et al., 2007). By using this hybrid technique, termed ETcaD, Molina et al. have demonstrated that $60 \%$ of nonmodified peptides identified from a tryptic digest of 48 proteins were from the doubly protonated precursor ions (Molina et al., 2008). Furthermore, it has been shown that ETcaD provides an improvement for nonmodified peptide identification (89\%) over CID (77\%) or ETD (63\%) alone (Swaney et al., 2007). In that study, ETcaD of doubly protonated phosphorylated peptide ions was also examined. Not surprisingly, the product ion formed from the neutral loss of $98 \mathrm{Da}$ was the most abundant ion present, while neutral losses of $98 \mathrm{Da}$ from the c- and z-type product ions were also observed (Swaney et al., 2007). As a result, the use of ETcaD could incur similar limitations for phosphorylation site assignment as conventional CID.

Since both the charge and length of the peptide ion largely affects ETD efficiency, Molina et al. (2007) have studied how the chosen proteolytic enzyme affects ETD for phosphoproteome analyses. In particular, they compared trypsin (cleavage $C$-terminal to arginine and lysine), Lys-C (cleavage $C$-terminal to lysine), and Glu-C (cleavage $C$-terminal to glutamic acid, and to a lesser extent aspartic acid). Due to the more limited cleavage specificity, it is expected that Lys-C would produce peptides with more basic residues and therefore higher charge than their trypsin counterparts, thereby increasing the number of phosphopeptides that could be identified using ETD. However, it was found that Lys-C and trypsin performed similarly. This was attributed to inefficient trypsin digestion near phosphorylated residues, resulting in phosphopeptides with similar peptide lengths and protonation states as Lys-C peptides (Molina et al., 2007). Molina et al. (2007) also studied the effects of Glu-C for ETD analysis of phosphopeptides, since the average peptide length produced by Glu-C digestion is thought to be between that of Lys-C and trypsin, and therefore would produce peptides suitable for ETD. However, due to poor cleavage specificity and efficiency, an order of magnitude less phosphopeptides were identified using Glu-C as compared with Lys-C and trypsin (Molina et al., 2007).

One limitation of ETD (as well as many of the other aforementioned MS/MS methods) is that it is generally not amenable to the analysis of peptide anions (Note added in proof: An effective negative ion ETD strategy for phosphopeptide anion characterization has recently been described by Huzarska et al. (2010)). Moreover, phosphopeptides tend to ionize better in negative ion mode than in positive ion mode, due to their relatively low isoelectric points (Janek et al., 2001). Considering these seemingly opposing points, Gunawardena, Emory, and McLuckey (2006) have demonstrated charge inversion of singly deprotonated phosphopeptide anions, by proton transfer reactions with multiply protonated amino-terminated dendrimers to form polycationic products in the gas phase for subsequent ETD analysis. This strategy was particularly beneficial because the phosphopeptides analyzed were either not present or present in low abundance in the corresponding positive ion mode MS spectra (Gunawardena, Emory, \& McLuckey, 2006).

c. Electron detachment dissociation (EDD). Electron detachment dissociation (EDD) is notable in that it allows for fragmentation of polyanions directly. EDD involves reaction of a polyanion with an electron $(>10 \mathrm{eV})$, inducing electron detachment and resulting in a charge-reduced radical anion
(Kjeldsen et al., 2005). Fragmentation of the radical anion is governed by radical reaction chemistry and produces a- and $\mathrm{x}$-type product ions via cleavage of the $\mathrm{C}_{\alpha}-\mathrm{C}_{\text {carbonyl }}$ bond (Kjeldsen et al., 2005; Kweon \& Hakansson, 2008). Like ETD and ECD, EDD is a rapid and relatively non-selective fragmentation method, and phosphorylated peptides generally retain their phosphate group upon dissociation, allowing for sequence and phosphorylation site assignment (Budnik, Haselmann, \& Zubarev, 2001; Kweon \& Hakansson, 2008). However, the fragmentation efficiency is generally lower than that of ETD or ECD (Kweon \& Hakansson, 2008). Figure 15 shows the EDD-MS/MS product ion spectrum of a doubly deprotonated peptide, FQpSEEQQQTEDELQDK. The observed sequence ions with intact phosphate groups comprise 9 of the 14 possible backbone cleavages and enable unambiguous phosphorylation site assignment (using the $\mathrm{x}_{13}$ and $\mathrm{x}_{14}$ product ions). Similar to ECD and ETD, the non-dissociated chargereduced radical species $\left([M-2 \mathrm{H}]^{-\cdot}\right)$ as well as an associated $\mathrm{CO}_{2}$ neutral loss species are also observed.

5. Metastable Atom-Activated Dissociation (MAD). Metastable atoms produced by either fast atom bombardment or a glow discharge source have also been used to impart energy to precursor peptide ions for fragmentation in a technique termed MAD or metastable-induced dissociation of ions (MIDI; Misharin et al., 2005; Berkout, 2006; Berkout \& Doroshenko, 2008; Cook, Collin, \& Jackson, 2009). Misharin et al. have shown that fragmentation of polycationic peptide ions with metastable helium or argon atoms in an ion trap gives rise to c- and z-type sequence ions, similar to ECD and ETD, and fragmentation of polyanionic peptide ions by similar methods gives rise to a- and $\mathrm{x}$-type sequence ions, similar to EDD (Misharin et al., 2005). As a result, two mechanisms for MAD have been proposed: for cations, electron transfer from the metastable atoms; and for anions, electron detachment and de-excitation of the metastable atom, that is, Penning ionization (see Eq. 1 where $\mathrm{m}^{*}$ is the metastable atom), each giving rise to radical-induced nonergodic peptide backbone fragmentation (Misharin et al., 2005). In addition, Berkout and Doroshenko demonstrated that singly protonated peptides also undergo fragmentation by interaction

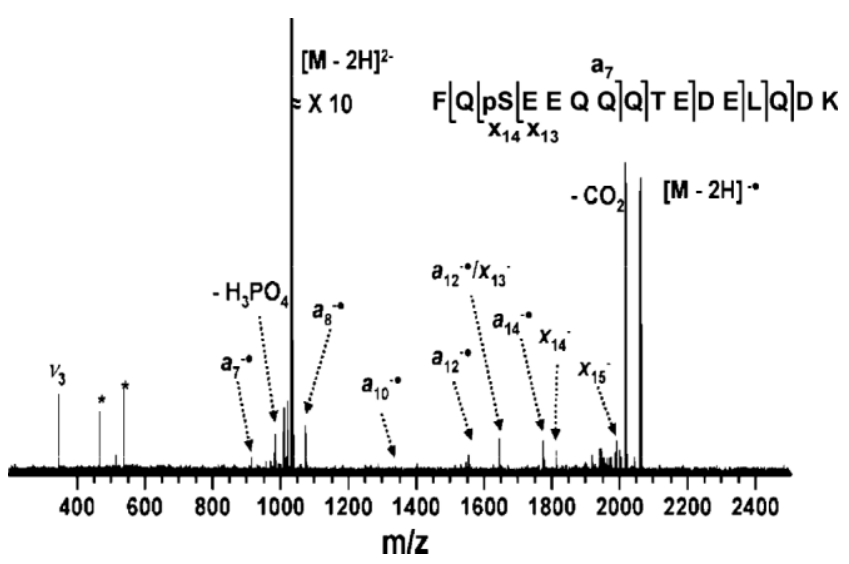

FIGURE 15. FTICR EDD-MS/MS spectrum of the doubly deprotonated precursor ion of FQpSEEQQQTEDELQDK. Reproduced from Kweon and Hakansson (2008) with permission from American Chemical Society, copyright 2008. 
with metastable atoms, substantiating the contribution of a Penning ionization mechanism (Berkout \& Doroshenko, 2008). Similarly, Cook, Collin, and Jackson (2009) have recently demonstrated extensive backbone fragmentation may be achieved by MAD of both singly and doubly protonated peptides. Notably, product ions including a-, b-, c-, x-, y-, z-types, consecutive side-chain and backbone cleavage ions ( $\mathrm{d}, \mathrm{v}$, and $\mathrm{w})$, and product ions resulting from through-ring cleavage of proline were all observed (Cook, Collin, \& Jackson, 2009)

$$
[M+n \mathrm{H}]^{n+}+\mathrm{m} * \rightarrow[M+n \mathrm{H}]^{(n+1)+}+\mathrm{m}+\mathrm{e}^{-}
$$

Importantly, the fragmentation of phosphorylated peptides by MAD results in the formation of phosphate-intact sequence ions, indicating that this technique may be useful for phosphoproteome analysis (Fig. 2(10); Berkout \& Doroshenko, 2008; Cook, Collin, \& Jackson, 2009). As an example, the MAD-MS/ MS product ion spectrum of a singly protonated phosphorylated cholecystokinin peptide (IKNLQpSLDPSH), using helium metastable atoms, is shown in Figure 16. The spectrum is rich with respect to the types of sequence ions formed (a-, b-, c-, $\mathrm{x}-$, and $y$-ions). Product ions resulting from side chain cleavages (circled) are also observed, adding to the complexity of the spectrum. Additionally, all of the observed sequence ions retained the phosphate group and nearly complete sequence coverage was obtained $(80 \%)$, allowing for unambiguous phosphorylation site assignment to the correct serine residue using the $\mathrm{x}_{5} / \mathrm{x}_{6}$ pair.

\section{Comparison of Tandem Mass Spectrometry Methods for} Phosphoproteome Analysis. Each of the MS/MS methods described above differs in their effectiveness for the analysis of phosphopeptides. In particular, they differ by the instrument platform which may be used, the precursor ions that are ammenable to dissociation, and the types of product ions that are formed (sequence vs. nonsequence, phosphate neutral loss, and phosphate group transfer). Consequently, not one technique has emerged as a universal method for phosphopeptide

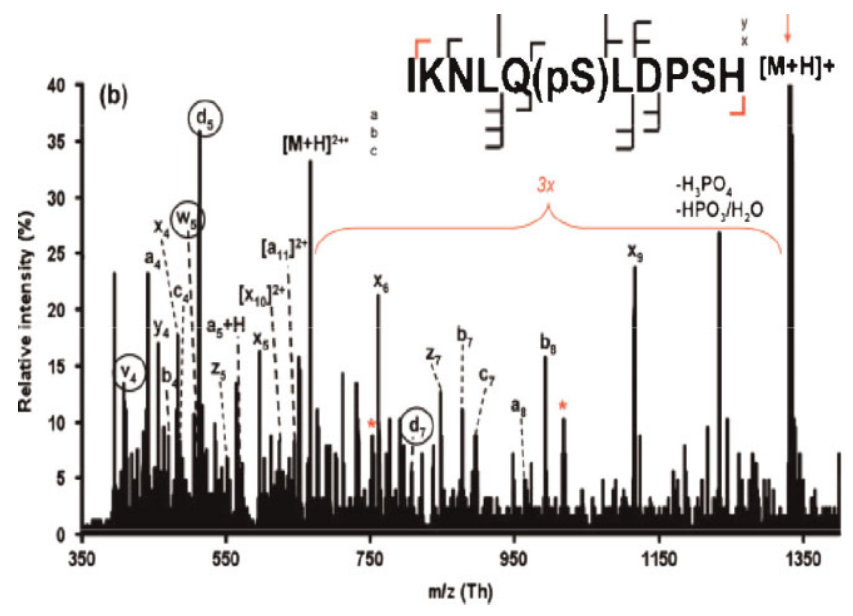

FIGURE 16. Ion trap MAD-MS/MS spectrum of the singly protonated precursor ion of IKNLQpSLDPSH (cholecystokinin) using a helium metastable atom beam. Side chain fragments are circled. Reproduced from Cook, Collin and Jackson (2009) with permission from John Wiley \& Sons, Inc., copyright 2009. [Color figure can be viewed in the online issue, which is available at wileyonlinelibrary.com] characterization. In fact, many studies comparing these MS/ MS methods have been completed and have consistently shown that many of the techniques produce complementary information.

For example, studies of nonphosphorylated peptides have reported that CID and ECD provide complementary sequence information, and that the application of both strategies provides a higher confidence in sequence assignment than can be attained with either technique alone (Stensballe et al., 2000; Shi et al., 2001). Moreover, a recent large-scale comparison of ECD and CID of tryptic phosphorylated peptides by Sweet et al. (2009) showed that although ECD gives rise to greater sequence coverage, it is highly complementary to the information made available by CID. However, for the purpose of unique phosphopeptide identification, it was also found that CID outperformed ECD (34\% vs. 13\%; Sweet et al., 2009). This was attributed to predominant production of doubly protonated precursor ions from the analysis of tryptic peptides, which are poor targets for electron dissociation techniques but are agreeable to CID. The ECD spectra, however, gave rise to more confident phosphorylation site localizations than the CID spectra (Sweet et al., 2009). The results of a small scale study on synthetic "tryptic" phosphopeptides comparing CID and ECD using a hybrid LTQ-FTICR instrument also agreed with the study by Sweet et al. (Stingl et al., 2006). Accordingly, combination techniques that use the strengths of both ECD and CID have proven successful for phosphoproteomic applications (Sweet, Creese, \& Cooper, 2006; Good et al., 2007; Bergström Lind et al., 2008; Sweet et al., 2008).

Other efforts toward comprehensive analyses have employed the combination of IRMPD and ECD since, as with the CID/ECD pairing, they also give rise to complementary structural information and hence allow for higher confidence in peptide identification (Hakansson et al., 2003). Additionally, similar to the AI-ECD, CID + ECD, and ETcaD methods, IRMPD of the non-dissociated charge-reduced radical cation species formed by ECD has also been performed to improve sequence coverage (Hakansson et al., 2003). This technique has further been applied to a tryptic phosphorylated peptide from protein kinase A (Chalmers et al., 2004). Interestingly, no product ions resulting from the neutral loss of $98 \mathrm{Da}$ were observed such that the phosphorylation site was easily identified (Chalmers et al., 2004).

The complementary nature of CID and ETD has also been demonstrated in a large-scale study on unmodified peptides by Good et al., where there was a $12 \%$ overlap in peptide identification between CID and ETD (Good et al., 2007). Swaney, McAlister, and Coon (2008) have shown that more peptides are identified using CID, but with lower sequence coverage as compared with ETD. Additionally, a large-scale comparison of ETD and CID for phosphoproteomic profiling of human embryonic kidney 293T cells completed by Molina et al. (2007) resulted in the identification of $60 \%$ of 312 phosphopeptides by ETD and $27 \%$ by CID. It should also be noted that although the product ions relating to the non-dissociated chargereduced cations were typically much more intense than the c-and z-ions in the resultant ETD spectra, ETD was still better for phosphopeptide identification than CID. Interestingly, this same study resulted in the identification of more nonphosphorylated peptides by CID than ETD. Importantly, due to the low amount of overlap between the two methods (13\%), the combination of 
ETD and CID data resulted in a greater number of identified phosphopeptides than could be determined from the individual techniques, and allowed $80 \%$ of the known phosphorylation sites to be observed from the sample (Molina et al., 2007).

Other complementary sequence information that CID, ECD/ ETD, and MAD provide relates to peptide backbone cleavage adjacent to proline residues. For CID of protonated peptide ions, amide bond cleavage $\mathrm{N}$-terminal to Pro may be a preferred cleavage site, whereas cleavage $C$-terminal to Pro is generally not observed (Steen \& Mann, 2004; Paizs \& Suhai, 2005). In contrast, for ECD/ETD, cleavage $C$-terminal to Pro is generally observed while cleavage to produce the corresponding $\mathrm{c}$ - and $\mathrm{z}$ ions on the $\mathrm{N}$-terminal side of Pro requires scission of two bonds and its observation has, therefore, remained rare (Cooper et al., 2003). This double cleavage has, however, been observed in other strategies such as MAD (Cook, Collin, \& Jackson, 2009).

The complementary sequence information that CID and ECD/ETD provides undoubtedly improves peptide identification. For phosphorylation site assignments, however, the information derived from CID and ECD/ETD spectra may largely overlap, despite the complications originating from the lability of the phosphate group by CID. This is because multiply protonated ions have a lower propensity to undergo phosphate group neutral losses and intramolecular phosphate group transfer upon CID (DeGnore \& Qin, 1998; Tholey, Reed, \& Lehmann, 1999; Palumbo \& Reid, 2008; Palumbo, Tepe, \& Reid, 2008; Villen, Beausoleil, \& Gygi, 2008), while conventional ECD/ETD are only amenable to the analysis of multiply protonated ions. This agreement in phosphorylation site assignment is demonstrated by comparing the CID-MS/MS product ion spectrum of the triply protonated HEVSASpTQpSTPASSR peptide shown in Figure 7C with the corresponding ETD-MS/MS spectrum shown in Figure 14. This synthetic peptide contains seven potential phosphorylation sites, two of which are occupied (Thr7 and Ser9). The phosphorylation sites are easily determined from the ETD-MS/MS spectrum due to the virtually complete sequence coverage obtained and the maintenance of the phosphate group. Initial inspection of the CID spectrum shows dominant nonsequence product ions resulting from neutral losses of 98 and $196 \mathrm{Da}$, demonstrating that the peptide is at least doubly phosphorylated. Despite these predominant neutral loss species, 12 of the 14 possible amide backbone cleavage ions are observed, including a series of $b$ - and y-ions with intact phosphate groups, and no product ions relating to gas phase intramolecular phosphate group transfer are present. As a result, the correct phosphorylation sites may be assigned, specifically using the $\mathrm{y}_{6} /$ $\mathrm{y}_{7}, \mathrm{~b}_{6} / \mathrm{b}_{7}$, and $\mathrm{b}_{8} / \mathrm{b}_{9}$ product ion pairs. It should be noted that the potentially complicating "dephosphorylated" sequence ions can also give some limited information relating to the correct locations of the phosphate groups in the CID spectrum. For example, in the b-ion series, only the $\mathrm{b}_{7}$ and higher ions resulted in the neutral loss of $98 \mathrm{Da}$ (or combinations of 98 and $\mathrm{H}_{2} \mathrm{O}$ ). These results may suggest that phosphorylation sites are located at position Thr7 and higher. Conversely however, it should be also noted that the lack of the presence of "dephosphorylated" sequence ions cannot be used to indicate that Ser4 and Ser6 are not phosphorylated. This "gray" area of phosphorylation site assignment regarding the phosphate neutral loss sequence ions perhaps allows rationalization as to why higher confidence in assignments have been previously demonstrated by ECD than CID (Sweet et al., 2009).
The spectral information available from newly emerging techniques for phosphopeptide analysis, such as UVPD, fsLID, EDD, and MAD may also be complementary to that obtained by the more established techniques, CID/PSD/IRMPD and ECD/ ETD. This is particularly true when considering the analysis of precursor ions with low protonation states (i.e., +1 or +2 ). Specifically, CID/PSD/IRMPD of precursor ions with low charge states exhibit the highest propensity for phosphate group neutral loss and phosphate group migration; and such precursor ions exhibit limited dissociation efficiency using ECD/ETD. The emerging techniques UVPD, fsLID, and MAD, on the other hand, are capable of dissociating low charge state peptides including those produced by MALDI. These complementary aspects of CID and ECD/ETD with fsLID are readily demonstrated by the comparison of the fsLID and CID spectra from the singly protonated LNQSpSPDNVTDTK peptide (Fig. 12). The CID spectrum is dominated by the nonsequence product ions corresponding to the neutral losses of the phosphate group, water, and combinations thereof, whereas the limited sequence ion coverage and observed phosphate group transfer product ion complicate the assignment. In contrast, the fsLID spectrum provides complete sequence coverage, with retention of the phosphate group in the correct location (i.e., no product ions resulting from phosphate group transfer are observed), allowing unambiguous determination of the correct phosphorylation site using the $\mathrm{x}_{7}, \mathrm{x}_{9}$, and $\mathrm{x}_{10}$ ions. Additionally, UVPD, MAD, and EDD enable the analysis of anionic phosphopeptides, which are not accessible by ECD/ETD, resulting in sequence information and/or phosphorylation-site specific information.

\section{CONCLUSIONS AND FUTURE OUTLOOK}

The applicability of MS/MS techniques for comprehensive phosphoproteome characterization is critically dependent on the gas phase ion chemistry associated with each technique. The as-yet hypothetical "ideal" technique for phosphoproteome analysis could be described as: (i) being globally applicable with regard to precursor ion structure or charge state, (ii) enabling facile differentiation between phosphorylated and nonphosphorylated peptides, and (iii) providing accurate, complete, and unambiguous sequence information for peptide identification and phosphorylation site assignment. Unfortunately, no existing technique has yet been demonstrated to fulfill all of these criteria simultaneously. As a result, the information achieved from complementary techniques may be required and care must be taken in the selection of techniques, with consideration of the nature of the precursor ions and the goals of the experiment. Future efforts to optimize newly emerging MS/MS methods, including increasing the fragmentation efficiency and fragmentation specificity, are likely to broaden the range of analytes that may be studied. Additionally, enhanced control of the chemistry in the gas phase might reasonably be addressed by "next generation" instrumentation or by improved derivatization techniques which allow the continued use of established ion activation techniques. Such improvements will undoubtedly be forthcoming, thereby leading to further maturation of MS/MS strategies with routine application toward phosphoproteome identification and characterization within the bioanalytical and biological research communities. 


\section{REFERENCES}

Ambihapathy K, Yalcin T, Leung H-W, Harrison AG. 1997. Pathways to immonium ions in the fragmentation of protonated peptides. J Mass Spectrom 32:209-215.

Andersson L, Porath J. 1986. Isolation of phosphoproteins by immobilized metal (fe-3+) affinity-chromatography. Anal Biochem 154:250-254.

Annan RS, Carr SA. 1996. Phosphopeptide analysis by matrix-assisted laser desorption time-of-flight mass spectrometry. Anal Chem 68:34133421

Annan RS, Huddleston MJ, Verma R, Deshaies RJ, Carr SA. 2001. A multidimensional electrospray MS-based approach to phosphopeptide mapping. Anal Chem 73:393-404.

Arrigoni G, Resjö S, Levander F, Nilsson R, Degerman E, Quadroni M, Pinna LA, James P. 2006. Chemical derivatization of phosphoserine and phosphothreonine containing peptides to increase sensitivity for MALDI-based analysis and for selectivity of MS/MS analysis. Proteomics 6:757-766.

Asara JM, Allison J. 1999. Enhanced detection of phosphopeptides in matrixassisted laser desorption/ionization mass spectrometry using ammonium salts. J Am Soc Mass Spectrom 10:35-44.

Baba T, Hashimoto Y, Hasegawa H, Hirabayashi A, Waki I. 2004. Electron capture dissociation in a radio frequency ion trap. Anal Chem 76:42634266

Beausoleil SA, Villen J, Gerber SA, Rush J, Gygi SP. 2006. A probabilitybased approach for high-throughput protein phosphorylation analysis and site localization. Nat Biotechnol 24:1285-1292.

Bergström Lind S, Molin M, Savitski MM, Emilsson L, Åström J, Hedberg L, Adams C, Nielsen ML, Engström Å, Elfineh L, Andersson E, Zubarev RA, Pettersson U. 2008. Immunoaffinity enrichments followed by mass spectrometric detection for studying global protein tyrosine phosphorylation. J Proteome Res 7:2897-2910.

Berkout VD. 2006. Fragmentation of protonated peptide ions via interaction with metastable atoms. Anal Chem 78:3055-3061.

Berkout VD, Doroshenko VM. 2008. Fragmentation of phosphorylated and singly charged peptide ions via interaction with metastable atoms. Int J Mass Spectrom 278:150-157.

Biemann K. 1988. Contributions of mass-spectrometry to peptide and protein-structure. Biomed Environ Mass Spectrom 16:99-111.

Bode AM, Dong Z. 2004. Post-translational modification of p53 in tumorigenesis. Nat Rev Cancer 4:793-805.

Boersema PJ, Mohammed S, Heck AJR. 2009. Phosphopeptide fragmentation and analysis by mass spectrometry. J Mass Spectrom 44:861-878.

Brill LM, Salomon AR, Ficarro SB, Mukherji M, Stettler-Gill M, Peters EC. 2004. Robust phosphoproteomic profiling of tyrosine phosphorylation sites from human t cells using immobilized metal affinity chromatography and tandem mass spectrometry. Anal Chem 76:2763-2772.

Brodbelt JS, Wilson JJ. 2009. Infrared multiphoton dissociation in quadrupole ion traps. Mass Spectrom Rev 28:390-424.

Budnik BA, Haselmann KF, Zubarev RA. 2001. Electron detachment dissociation of peptide di-anions: An electron-hole recombination phenomenon. Chem Phys Lett 342:299-302.

Bushey JM, Baba T, Glish GL. 2009. Simultaneous collision induced dissociation of the charge reduced parent ion during electron capture dissociation. Anal Chem 81:6156-6164.

Carr SA, Huddleston MJ, Annan RS. 1996. Selective detection and sequencing of phosphopeptides at the femtomole level by mass spectrometry. Anal Biochem 239:180-192.

Carr SA, Annan RS, Huddleston MJ. 2005. Mapping posttranslational modifications of proteins by MS-based selective detection: Application to phosphoproteomics. Methods Enzymol 405:82-115.

Chalmers MJ, Quinn JP, Blakney GT, Emmett MR, Mischak H, Gaskell SJ, Marshall AG. 2003. Liquid chromatography-Fourier transform ion cyclotron resonance mass spectrometric characterization of protein kinase c phosphorylation. J Proteome Res 2:373-382.
Chalmers MJ, Hakansson K, Johnson R, Smith R, Shen JW, Emmett MR, Marshall AG. 2004. Protein kinase a phosphorylation characterized by tandem Fourier transform ion cyclotron resonance mass spectrometry. Proteomics 4:970-981.

Chang EJ, Archambault V, McLachlin DT, Krutchinsky AN, Chait BT. 2004. Analysis of protein phosphorylation by hypothesis-driven multiplestage mass spectrometry. Anal Chem 76:4472-4483.

Chi A, Huttenhower C, Geer LY, Coon JJ, Syka JEP, Bai DL, Shabanowitz J, Burke DJ, Troyanskaya OG, Hunt DF. 2007. Analysis of phosphorylation sites on proteins from Saccharomyces cerevisiae by electron transfer dissociation (ETD) mass spectrometry. Proc Natl Acad Sci USA 104:2193-2198.

Clark MP, Bookland RG. 2005. Pyrazolones as therapeutics for kinasemediated inflammatory disorders. Expert Opin Ther Pat 15:1617-1623.

Cohen P. 2000. The regulation of protein function by multisite phosphorylation-A 25 year update. Trends Biochem Sci 25:596-601.

Collins MO, Yu L, Coba MP, Husi H, Campuzano L, Blackstock WP, Choudhary JS, Grant SGN. 2005. Proteomic analysis of in vivo phosphorylated synaptic proteins. J Biol Chem 280:5972-5982.

Cook SL, Collin OL, Jackson GP. 2009. Metastable atom-activated dissociation mass spectrometry: Leucine/isoleucine differentiation and ring cleavage of proline residues. J Mass Spectrom 44:1211-1223.

Cooper HJ, Hudgins RR, Håkansson K, Marshall AG. 2003. Secondary fragmentation of linear peptides in electron capture dissociation. Int $\mathrm{J}$ Mass Spectrom 228:723-728.

Cooper HJ, Håkansson K, Marshall AG. 2005. The role of electron capture dissociation in biomolecular analysis. Mass Spectrom Rev 24:201-222.

Cox KA, Gaskell SJ, Morris M, Whiting A. 1996. Role of the site of protonation in the low-energy decompositions of gas-phase peptide ions. J Am Soc Mass Spectrom 7:522-531.

Craig AG, Hoeger CA, Miller CL, Goedken T, Rivier JE, Fischer WH. 1994. Monitoring protein-kinase and phosphatase reactions with matrixassisted laser-desorption ionization mass-spectrometry and capillary zone electrophoresis-Comparison of the detection efficiency of peptide-phosphopeptide mixtures. Biol Mass Spectrom 23:519-528.

Crowe MC, Brodbelt JS. 2004. Infrared multiphoton dissociation (IRMPD) and collisionally activated dissociationof peptides in a quadrupole ion trap with selective IRMPD of phosphopeptides. J Am Soc Mass Spectrom 15:1581-1592.

Csonka IP, Paizs B, Lendvay G, Suhai S. 2000. Proton mobility in protonated peptides: A joint molecular orbital and RRKM study. Rapid Commun Mass Spectrom 14:417-431.

Culmsee C, Landshamer S. 2006. Molecular insights into mechanisms of the cell death program: Role in the progression of neurodegenerative disorders. Curr Alzheimer Res 3:269-283.

DeGnore JP, Qin J. 1998. Fragmentation of phosphopeptides in an ion trap mass spectrometer. J Am Soc Mass Spectrom 9:1175-1188.

Diedrich JK, Julian RR. 2008. Site-specific radical directed dissociation of peptides at phosphorylated residues. J Am Chem Soc 130:12212-12213.

Ding L, Brancia FL. 2006. Electron capture dissociation in a digital ion trap mass spectrometer. Anal Chem 78:1995-2000.

Ding J, Burkhart W, Kassel DB. 1994. Identification of phosphorylated peptides from complex mixtures using negative-ion orifice-potential stepping and capillary liquid chromatography/electrospray ionization mass spectrometry. Rapid Commun Mass Spectrom 8:94-98.

Dongre AR, Jones JL, Somogyi A, Wysocki VH. 1996. Influence of peptide composition, gas-phase basicity, and chemical modification on fragmentation efficiency: Evidence for the mobile proton model. J Am Chem Soc 118:8365-8374.

Ducruet AP, Vogt A, Wipf P, Lazo JS. 2005. Dual specificity protein phosphatases: Therapeutic targets for cancer and Alzheimer's disease. Annu Rev Pharmacol Toxicol 45:725-750.

Dunn JD, Reid GE, Bruening ML. 2010. Techniques for phosphopeptide enrichment prior to analysis by mass spectrometry. Mass Spectrom Rev 29:29-54. 
Echols N, Harrison P, Balasubramanian S, Luscombe NM, Bertone P, Zhang Z, Gerstein M. 2002. Comprehensive analysis of amino acid and nucleotide composition in eukaryotic genomes, comparing genes and pseudogenes. Nucl Acids Res 30:2515-2523.

Edelson-Averbukh M, Pipkorn R, Lehmann WD. 2006. Phosphate groupdriven fragmentation of multiply charged phosphopeptide anions. Improved recognition of peptides phosphorylated at serine, threonine, or tyrosine by negative ion electrospray tandem mass spectrometry. Anal Chem 78:1249-1256.

Edelson-Averbukh M, Shevchenko A, Pipkorn Rd, Lehmann WD. 2009. Gasphase intramolecular phosphate shift in phosphotyrosine-containing peptide monoanions. Anal Chem 81:4369-4381.

Eyler JR. 2009. Infrared multiple photon dissociation spectroscopy of ions in penning traps. Mass Spectrom Rev 28:448-467.

Ficarro SB, McCleland ML, Stukenberg PT, Burke DJ, Ross MM, Shabanowitz J, Hunt DF, White FM. 2002. Phosphoproteome analysis by mass spectrometry and its application to saccharomyces cerevisiae. Nat Biotechnol 20:301-305.

Ficarro S, Chertihin O, Westbrook VA, White F, Jayes F, Kalab P, Marto JA, Shabanowitz J, Herr JC, Hunt DF, Visconti PE. 2003. Phosphoproteome analysis of capacitated human sperm. Evidence of tyrosine phosphorylation of a kinase-anchoring protein 3 and valosin-containing protein/ p97 during capacitation. J Biol Chem 278:11579-11589.

Flora JW, Muddiman DC. 2001. Selective, sensitive, and rapid phosphopeptide identification in enzymatic digests using ESI-FTICR-MS with infrared multiphoton dissociation. Anal Chem 73:3305-3311.

Flora JW, Muddiman DC. 2002. Gas-phase ion unimolecular dissociation for rapid phosphopeptide mapping by IRMPD in a penning ion trap: An energetically favored process. J Am Chem Soc 124:6546-6547.

Flora JW, Muddiman DC. 2004. Determination of the relative energies of activation for the dissociation of aromatic versus aliphatic phosphopeptides by ESI-FTICR-MS and IRMPD. J Am Soc Mass Spectrom 15:121-127.

Frawley SM, Reid GE, Tepe JJ. 2009. Synthesis of diazo functionalized solid supports and their application towards the enrichment of phosphorylated peptides. Org Biomol Chem 7:3291-3299.

Frawley Cass SM, Reid GE, Tepe JJ. 2010. Identification of phosphoproteins and their impact as biomarkers in cancer therapeutics. Curr Signal Transduction Ther in press.

Fung YME, Adams CM, Zubarev RA. 2009. Electron ionization dissociation of singly and multiply charged peptides. J Am Chem Soc 131:99779985.

Gehrig PM, Roschitzki1 B, Rutishauser D, Reiland S, Schlapbach R. 2009. Phosphorylated serine and threonine residues promote site-specific fragmentation of singly charged, arginine containing peptide ions. Rapid Commun Mass Spectrom 23:1435-1445.

Gong CX, Iqbal K. 2008. Hyperphosphorylation of microtubule-associated protein tau: A promising therapeutic target for Alzheimer disease. Curr Med Chem 15:2321-2328.

Gong C-X, Liu F, Grundke-Iqbal I, Iqbal K. 2006. Dysregulation of protein phosphorylation/dephosphorylation in Alzheimer's disease: A therapeutic target. J Biomed Biotechnol 2006:1-11.

Good DM, Wirtala M, McAlister GC, Coon JJ. 2007. Performance characteristics of electron transfer dissociation mass spectrometry. Mol Cell Proteomics 6:1942-1951.

Goshe MB. 2006. Characterizing phosphoproteins and phosphoproteomes using mass spectrometry. Brief Funct Genomics Proteomics 4:363376.

Goshe MB, Conrads TP, Panisko EA, Angell NH, Veenstra TD, Smith RD. 2001. Phosphoprotein isotope-coded affinity tag approach for isolating and quantitating phosphopeptides in proteome-wide analyses. Anal Chem 73:2578-2586.

Gronert S, Huang R, Li KH. 2004. Gas phase derivatization in peptide analysis I: The utility of trimethyl borate in identifying phosphorylation sites. Int J Mass Spectrom 231:179-187.
Gronert S, Li KH, Horiuchi M. 2005. Manipulating the fragmentation patterns of phosphopeptides via gas-phase boron derivatization: Determining phosphorylation sites in peptides with multiple serines. J Am Soc Mass Spectrom 16:1905-1914.

Gunawardena HP, He M, Chrisman PA, Pitteri SJ, Hogan JM, Hodges BDM, McLuckey SA. 2005. Electron transfer versus proton transfer in gasphase ion/ion reactions of polyprotonated peptides. J Am Chem Soc 127:12627-12639.

Gunawardena HP, Emory JF, McLuckey SA. 2006. Phosphopeptide anion characterization via sequential charge inversion and electron-transfer dissociation. Anal Chem 78:3788-3793.

Hakansson K, Chalmers MJ, Quinn JP, McFarland MA, Hendrickson CL, Marshall AG. 2003. Combined electron capture and infrared multiphoton dissociation for multistage MS/MS in a Fourier transform ion cyclotron resonance mass spectrometer. Anal Chem 75:3256-3262.

Hoffman MD, Sniatynski MJ, Rogalski JC, Le Blanc JCY, Kast J. 2006. Multiple neutral loss monitoring (MNM): A multiplexed method for post-translational modification screening. J Am Soc Mass Spectrom $17: 307-317$

Hoffmann R, Metzger S, Spengler B, Otvos L, Jr. 1999. Sequencing of peptides phosphorylated on serines and threonines by post-source decay in matrix-assisted laser desorption/ionization time-of-flight mass spectrometry. J Mass Spectrom 34:1195-1204.

Hohmann LJ, Eng JK, Gemmill A, Klimek J, Vitek O, Reid GE, Martin DB. 2008. Quantification of the compositional information provided by immonium ions on a quadrupole-time-of-flight mass spectrometer. Anal Chem 80:5596-5606.

Horn DM, Ge Y, McLafferty FW. 2000a. Activated ion electron capture dissociation for mass spectral sequencing of larger $(42 \mathrm{kDa})$ proteins. Anal Chem 72:4778-4784.

Horn DM, Zubarev RA, McLafferty FW. 2000b. Automated de novo sequencing of proteins by tandem high-resolution mass spectrometry. Proc Natl Acad Sci USA 97:10313-10317.

Huddleston MJ, Annan RS, Bean MF, Carr SA. 1993. Selective detection of phosphopeptides in complex mixtures by electrospray liquid chromatography/mass spectrometry. J Am Soc Mass Spectrom 4:710-717.

Hunter T. 2000. Signaling-2000 and beyond. Cell 100:113-127.

Huzarska M, Ugalde I, Kaplan DA, Hartmer R, Easterling ML, Polfer NC. 2010. Negative electron transfer dissociation of deprotonated phosphopeptide anions: Choice of radical cation reagent and competition between electron and proton transfer. Anal Chem 82:2873-2878.

Ikeguchi Y, Nakamura H. 1997. Determination of organic phosphates by column-switching high performance anion-exchange chromatography using on-line preconcentration on titania. Anal Sci 13:479-483.

Jackson SN, Wang H-YJ, Woods AS. 2005. Study of the fragmentation patterns of the phosphate-arginine noncovalent bond. J Proteome Res 4:2360-2363.

Jackson SN, Wang HYJ, Yergey A, Woods AS. 2006. Phosphate stabilization of intermolecular interactions. J Proteome Res 5:122-126.

Jackson SN, Moyer SC, Woods AS. 2008. The role of phosphorylated residues in peptide-peptide noncovalent complexes formation. J Am Soc Mass Spectrom 19:1535-1541.

Janek K, Wenschuh H, Bienert M, Krause E. 2001. Phosphopeptide analysis by positive and negative ion matrix-assisted laser desorption/ionization mass spectrometry. Rapid Commun Mass Spectrom 15:1593-1599.

Kalcic CL, Gunaratne TC, Jones AD, Dantus M, Reid GE. 2009. Femtosecond laser-induced ionization/dissociation of protonated peptides. J Am Chem Soc 131:940-942.

Kapp EA, Schutz F, Reid GE, Eddes JS, Moritz RL, O'Hair RAJ, Speed TP, Simpson RJ. 2003. Mining a tandem mass spectrometry database to determine the trends and global factors influencing peptide fragmentation. Anal Chem 75:6251-6264.

Kaufmann R, Spengler B, Lutzenkirchen F. 1993. Mass-spectrometric sequencing of linear peptides by product-ion analysis in a reflectron time-of-flight mass-spectrometer using matrix-assisted 
laser-desorption ionization. Rapid Commun Mass Spectrom 7:902910

Kewalramani G, An D, Kim MS, Ghosh S, Qi D, Abrahani A, Pulinilkunnil T, Sharma V, Wambolt RB, Allard MF, Innis SM, Rodrigues B. 2007. AMPK control of myocardial fatty acid metabolism fluctuates with the intensity of insulin-deficient diabetes. J Mol Cell Cardiol 42:333-342.

Kim T-Y, Reilly JP. 2009. Time-resolved observation of product ions generated by $157 \mathrm{~nm}$ photodissociation of singly protonated phosphopeptides. J Am Soc Mass Spectrom 20:2334-2341.

Kjeldsen F, Silivra OA, Ivonin IA, Haselmann KF, Gorshkov M, Zubarev RA. 2005. C alpha-C backbone fragmentation dominates in electron detachment dissociation of gas-phase polypeptide polyanions. Chem Eur J 11:1803-1812.

Knight ZA, Schilling B, Row RH, Kenski DM, Gibson BW, Shokat KM. 2003. Phosphospecific proteolysis for mapping sites of protein phosphorylation. Nat Biotechnol 21:1047-1054.

Kocher T, Savitski MM, Nielsen ML, Zubarev RA. 2006. Phostshunter: A fast and reliable tool to detect phosphorylated peptides in liquid chromatography Fourier transform tandem mass spectrometry data sets. J Proteome Res 5:659-668.

Kokubu M, Ishihama Y, Sato T, Nagasu T, Oda Y. 2005. Specificity of immobilized metal affinity-based IMAC/C18 tip enrichment of phosphopeptides for protein phosphorylation analysis. Anal Chem 77:5144-5154.

Kuyama H, Sonomura K, Nishimura O. 2008. Sensitive detection of phosphopeptides by matrix-assisted laser desorption/ionization mass spectrometry: Use of alkylphosphonic acids as matrix additives. Rapid Commun Mass Spectrom 22:1109-1116.

Kweon HK, Hakansson K. 2006. Selective zirconium dioxide-based enrichment of phosphorylated peptides for mass spectrometric analysis. Anal Chem 78:1743-1749.

Kweon HK, Hakansson K. 2008. Metal oxide-based enrichment combined with gas-phase ion-electron reactions for improved mass spectrometric characterization of protein phosphorylation. J Proteome Res 7:749755 .

Lansdell TA, Tepe JJ. 2004. Isolation of phosphopeptides using solid phase enrichment. Tetrahedron Lett 45:91-93.

Larsen MR, Sorensen GL, Fey SJ, Larsen PM, Roepstorff P. 2001. Phosphoproteomics: Evaluation of the use of enzymatic de-phosphorylation and differential mass spectrometric peptide mass mapping for site specific phosphorylation assignment in proteins separated by gel electrophoresis. Proteomics 1:223-238.

Larsen MR, Thingholm TE, Jensen ON, Roepstorff P, Jorgensen TJD. 2005. Highly selective enrichment of phosphorylated peptides from peptide mixtures using titanium dioxide microcolumns. Mol Cell Proteomics $4: 873-886$.

Lee J, Xu Y, Chen Y, Sprung R, Kim SC, Xie S, Zhao Y. 2007. Mitochondrial phosphoproteome revealed by an improved IMAC method and MS/MS/ MS. Mol Cell Proteomics 6:669-676.

Lehmann WD, Krueger R, Salek M, Hung C-W, Wolschin F, Weckwerth W. 2007. Neutral loss-based phosphopeptide recognition: A collection of caveats. J Proteome Res 6:2866-2873.

Leitner A, Foettinger A, Lindner W. 2007. Improving fragmentation of poorly fragmenting peptides and phosphopeptides during collision-induced dissociation by malondialdehyde modification of arginine residues. J Mass Spectrom 42:950-959.

Lemoine J, Tabarin T, Antoine R, Broyer M, Dugourd P. 2006. UV photodissociation of phospho-seryl-containing peptides: Laser stabilization of the phospho-seryl bond with multistage mass spectrometry. Rapid Commun Mass Spectrom 20:507-511.

Li X, Gerber SA, Rudner AD, Beausoleil SA, Haas W, Villen J, Elias JE, Gygi SP. 2007. Large-scale phosphorylation analysis of $\alpha$-factor-arrested saccharomyces cerevisiae. J Proteome Res 6:1190-1197.

Liao PC, Leykam J, Andrews PC, Gage DA, Allison J. 1994. An approach to locate phosphorylation sites in a phosphoprotein - mass mapping by combining specific enzymatic degradation with matrix-assisted laserdesorption ionization mass-spectrometry. Anal Biochem 219:9-20.

Little DP, Speir JP, Senko MW, Oconnor PB, Mclafferty FW. 1994. Infrared multiphoton dissociation of large multiply-charged ions for biomolecule sequencing. Anal Chem 66:2809-2815.

Lu B, Ruse C, Xu T, Park SK, Yates J. 2007. Automatic validation of phosphopeptide identifications from tandem mass spectra. Anal Chem 79:1301-1310.

Macek B, Mijakovic I, Olsen JV, Gnad F, Kumar C, Jensen PR, Mann M. 2007. The serine/threonine/tyrosine phosphoproteome of the model bacterium bacillus subtilis. Mol Cell Proteomics 6:697-707.

Mackay HJ, Twelves CJ. 2007. Targeting the protein kinase c family: Are we there yet? Nat Rev Cancer 7:554-562.

Mann M, Jensen ON. 2003. Proteomic analysis of post-translational modifications. Nat Biotechnol 21:255-261.

Matsuda H, Nakamura H, Nakajima T. 1990. New ceramic titania-Selective adsorbent for organic-phosphates. Anal Sci 6:911-912.

Matthiesen R, Trelle MB, Hojrup P, Bunkenborg J, Jensen ON. 2005. Vems 3.0: Algorithms and computational tools for tandem mass spectrometry based identification of post-translational modifications in proteins. J Proteome Res 4:2338-2347.

Mazanetz MP, Fischer PM. 2007. Untangling tau hyperphosphorylation in drug design for neurodegenerative diseases. Nat Rev Drug Discov 6:464-479.

McLachlin DT, Chait BT. 2001. Analysis of phosphorylated proteins and peptides by mass spectrometry. Curr Opin Chem Biol 5:591-602.

McLachlin DT, Chait BT. 2003. Improved $\beta$-elimination-based affinity purification strategy for enrichment of phosphopeptides. Anal Chem 75:6826-6836.

McLafferty FW, Horn DM, Breuker K, Ge Y, Lewis MA, Cerda B, Zubarev RA, Carpenter BK. 2001. Electron capture dissociation of gaseous multiply charged ions by Fourier-transform ion cyclotron resonance. J Am Soc Mass Spectrom 12:245-249.

McLuckey SA, Goeringer DE. 1997. Slow heating methods in tandem mass spectrometry. J Mass Spectrom 32:461-474.

Metzger S, Hoffmann R. 2000. Studies on the dephosphorylation of phosphotyrosine-containing peptides during post-source decay in matrix-assisted laser desorption/ionization. J Mass Spectrom 35: $1165-1177$

Meyer HE, Hoffmann-Posorske E, Korte H, Heilmeyer LMG. 1986. Sequence-analysis of phosphoserine-containing peptides - modification for picomolar sensitivity. FEBS Lett 204:61-66.

Misharin AS, Silivra OA, Kjeldsen F, Zubarev RA. 2005. Dissociation of peptide ions by fast atom bombardment in a quadrupole ion trap. Rapid Commun Mass Spectrom 19:2163-2171.

Molina H, Horn DM, Tang N, Mathivanan S, Pandey A. 2007. Global proteomic profiling of phosphopeptides using electron transfer dissociation tandem mass spectrometry. Proc Natl Acad Sci USA 104:2199-2204.

Molina H, Matthiesen R, Kandasamy K, Pandey A. 2008. Comprehensive comparison of collision induced dissociation and electron transfer dissociation. Anal Chem 80:4825-4835.

Moon JH, Shin YS, Kim MS. 2009. Utility of reaction intermediate monitoring with photodissociation multi-stage $\left(\mathrm{MS}^{n}\right)$ time-of-flight mass spectrometry for mechanistic and structural studies: Phosphopeptides. Int J Mass Spectrom 288:16-21.

Moyer SC, Cotter RJ, Woods AS. 2002. Fragmentation of phosphopeptides by atmospheric pressure MALDI and ESI/ion trap mass spectrometry. J Am Soc Mass Spectrom 13:274-283.

Ndassa YM, Orsi C, Marto JA, Chen S, Ross MM. 2006. Improved immobilized metal affinity chromatography for large-scale phosphoproteomics applications. J Proteome Res 5:2789-2799.

Nielsen ML, Savitski MM, Zubarev RA. 2005. Improving protein identification using complementary fragmentation techniques in Fourier transform mass spectrometry. Mol Cell Proteomics 4:835-845. 
Nita-Lazar A, Saito-Benz H, White FM. 2008. Quantitative phosphoproteomics by mass spectrometry: Past, present, and future. Proteomics 8 : $4433-4443$.

Oda Y, Nagasu T, Chait BT. 2001. Enrichment analysis of phosphorylated proteins as a tool for probing the phosphoproteome. Nat Biotechnol 19:379-382.

Olsen JV, Blagoev B, Gnad F, Macek B, Kumar C, Mortensen P, Mann M. 2006. Global, in vivo, and site-specific phosphorylation dynamics in signaling networks. Cell 127:635-648.

Paizs B, Suhai S. 2005. Fragmentation pathways of protonated peptides. Mass Spectrom Rev 24:508-548.

Paizs B, Lendvay G, Vekey K, Suhai S. 1999. Formation of b2 ${ }^{+}$ions from protonated peptides: An ab initio study. Rapid Commun Mass Spectrom 13:525-533.

Palumbo AM, Reid GE. 2008. Evaluation of gas-phase rearrangement and competing fragmentation reactions on protein phosphorylation site assignment using collision induced dissociation-ms/ms and $\mathrm{ms} 3$. Anal Chem 80:9735-9747.

Palumbo AM, Tepe JJ, Reid GE. 2008. Mechanistic insights into the multistage gas-phase fragmentation behavior of phosphoserine- and phosphothreonine-containing peptides. J Proteome Res 7:771-779.

Pandey A, Podtelejnikov AV, Blagoev B, Bustelo XR, Mann M, Lodish HF. 2000. Analysis of receptor signaling pathways by mass spectrometry: Identification of vav-2 as a substrate of the epidermal and plateletderived growth factor receptors. Proc Natl Acad Sci USA 97:179184.

Paradela A, Albar JP. 2008. Advances in the analysis of protein phosphorylation. J Proteome Res 7:1809-1818.

Pinkse MWH, Uitto PM, Hilhorst MJ, Ooms B, Heck AJR. 2004. Selective isolation at the femtomole level of phosphopeptides from proteolytic digests using 2d-nanolc-ESI-MS/MS and titanium oxide precolumns. Anal Chem 76:3935-3943.

Posewitz MC, Tempst P. 1999. Immobilized gallium(III) affinity chromatography of phosphopeptides. Anal Chem 71:2883-2892.

Pyatkivskyy Y, Ryzhov V. 2008. Coupling of ion-molecule reactions with liquid chromatography on a quadrupole ion trap mass spectrometer. Rapid Commun Mass Spectrom 22:1288-1294.

Qin J, Chait BT. 1997. Identification and characterization of posttranslational modifications of proteins by MALDI ion trap mass spectrometry. Anal Chem 69:4002-4009.

Reid GE, Simpson RJ, O'Hair RAJ. 2000. Leaving group and gas phase neighboring group effects in the side chain losses from protonated serine and its derivatives. J Am Soc Mass Spectrom 11:1047-1060.

Reilly JP. 2009. Ultraviolet photofragmentation of biomolecular ions. Mass Spectrom Rev 28:425-447.

Roepstorff P, Fohlman J. 1984. Proposal for a common nomenclature for sequence ions in mass spectra of peptides. Biomed Mass Spectrom 11:601.

Rouse JC, Yu W, Martin SA. 1995. A comparison of the peptide fragmentation obtained from a reflector matrix-assisted laser desorption-ionization time-of-flight and a tandem 4-sector mass-spectrometer. J Am Soc Mass Spectrom 6:822-835.

Rush J, Moritz A, Lee KA, Guo A, Goss VL, Spek EJ, Zhang H, Zha X-M, Polakiewicz RD, Comb MJ. 2005. Immunoaffinity profiling of tyrosine phosphorylation in cancer cells. Nat Biotechnol 23:94-101.

Salek M, Alonso A, Pipkorn R, Lehmann WD. 2003. Analysis of protein tyrosine phosphorylation by nanoelectrospray ionization high-resolution tandem mass spectrometry and tyrosine-targeted product ion scanning. Anal Chem 75:2724-2729.

Satake H, Hasegawa H, Hirabayashi A, Hashimoto Y, Baba T, Masuda K. 2007. Fast multiple electron capture dissociation in a linear radio frequency quadrupole ion trap. Anal Chem 79:8755-8761.

Schlosser A, Pipkorn R, Bossemeyer D, Lehmann WD. 2001. Analysis of protein phosphorylation by a combination of elastase digestion and neutral loss tandem mass spectrometry. Anal Chem 73:170-176.
Schnolzer M, Lehmann WD. 1997. Identification of modified peptides by metastable fragmentation in MALDI mass spectrometry. Int J Mass Spectrom Ion Processes 169/170:263-271.

Schreiber TB, Mausbacher N, Breitkopf SB, Grundner-Culemann K, Daub H. 2008. Quantitative phosphoproteomics-An emerging key technology in signal-transduction research. Proteomics 8:4416-4432.

Schroeder MJ, Shabanowitz J, Schwartz JC, Hunt DF, Coon JJ. 2004. A neutral loss activation method for improved phosphopeptide sequence analysis by quadrupole ion trap mass spectrometry. Anal Chem 76:3590-3598.

Shi SDH, Hemling ME, Carr SA, Horn DM, Lindh I, McLafferty FW. 2001. Phosphopeptide/phosphoprotein mapping by electron capture dissociation mass spectrometry. Anal Chem 73:19-22.

Shin YS, Moon JH, Kim MS. 2010. Observation of phosphorylation sitespecific dissociation of singly protonated phosphopeptides. J Am Soc Mass Spectrom 21:53-59.

Silivra OA, Kjeldsen F, Ivonin IA, Zubarev RA. 2005. Electron capture dissociation of polypeptides in a three-dimensional quadrupole ion trap: Implementation and first results. J Am Soc Mass Spectrom 16:22-27.

Spengler B. 1997. Post-source decay analysis in matrix-assisted laser desorption/ionization mass spectrometry of biomolecules. J Mass Spectrom 32:1019-1036.

Steen H, Mann M. 2002. A new derivatization strategy for the analysis of phosphopeptides by precursor ion scanning in positive ion mode. J Am Soc Mass Spectrom 13:996-1003.

Steen H, Mann M. 2004. The abc's (and xyz's) of peptide sequencing. Nat Rev Mol Cell Biol 5:699-711.

Steen H, Kuster B, Fernandez M, Pandey A, Mann M. 2001a. Detection of tyrosine phosphorylated peptides by precursor ion scanning quadrupole TOF mass spectrometry in positive ion mode. Anal Chem 73:14401448.

Steen H, Kuster B, Mann M. 2001b. Quadrupole time-of-flight versus triplequadrupole mass spectrometry for the determination of phosphopeptides by precursor ion scanning. J Mass Spectrom 36:782-790.

Steen H, Kuster B, Fernandez M, Pandey A, Mann M. 2002. Tyrosine phosphorylation mapping of the epidermal growth factor receptor signaling pathway. J Biol Chem 277:1031-1039.

Steen H, Jebanathirajah JA, Rush J, Morrice N, Kirschner MW. 2006. Phosphorylation analysis by mass spectrometry - myths, facts, and the consequences for qualitative and quantitative measurements. Mol Cell Proteomics 5:172-181.

Stensballe A, Jensen ON. 2004. Phosphoric acid enhances the performance of $\mathrm{Fe}(\mathrm{III})$ affinity chromatography and matrix-assisted laser desorption/ ionization tandem mass spectrometry for recovery, detection and sequencing of phosphopeptides. Rapid Commun Mass Spectrom 18:1721-1730.

Stensballe A, Jensen ON, Olsen JV, Haselmann KF, Zubarev RA. 2000. Electron capture dissociation of singly and multiply phosphorylated peptides. Rapid Commun Mass Spectrom 14:1793-1800.

Stingl C, Ihling C, Ammerer G, Sinz A, Mechtler K. 2006. Application of different fragmentation techniques for the analysis of phosphopeptides using a hybrid linear ion trap-FTICR mass spectrometer. BBA-Proteins Proteom 1764:1842-1852.

Swaney DL, McAlister GC, Wirtala M, Schwartz JC, Syka JEP, Coon JJ. 2007. Supplemental activation method for high-efficiency electrontransfer dissociation of doubly protonated peptide precursors. Anal Chem 79:477-485.

Swaney DL, McAlister GC, Coon JJ. 2008. Decision tree-driven tandem mass spectrometry for shotgun proteomics. Nat Meth 5:959-964.

Swaney DL, Wenger CD, Thomson JA, Coon JJ. 2009. Human embryonic stem cell phosphoproteome revealed by electron transfer dissociation tandem mass spectrometry. Proc Natl Acad Sci USA 106:995-1000.

Sweet SMM, Cooper Helen J. 2009. On-line liquid chromatography electron capture dissociation for the characterization of phosphorylation sites in proteins. Methods Mol Biol 527:191-199. 
Sweet SMM, Creese AJ, Cooper HJ. 2006. Strategy for the identification of sites of phosphorylation in proteins: Neutral loss triggered electron capture dissociation. Anal Chem 78:7563-7569.

Sweet SMM, Mardakheh FK, Ryan KJP, Langton AJ, Heath JK, Cooper HJ. 2008. Targeted online liquid chromatography electron capture dissociation mass spectrometry for the localization of sites of in vivo phosphorylation in human sprouty2. Anal Chem 80:66506657.

Sweet SMM, Bailey CM, Cunningham DL, Heath JK, Cooper HJ. 2009. Large scale localization of protein phosphorylation by use of electron capture dissociation mass spectrometry. Mol Cell Proteomics 8:904912.

Syka JEP, Coon JJ, Schroeder MJ, Shabanowitz J, Hunt DF. 2004. Peptide and protein sequence analysis by electron transfer dissociation mass spectrometry. Proc Natl Acad Sci USA 101:95289533.

Tabarin T, Antoine R, Broyer M, Dugourd P. 2005. Specific photodissociation of peptides with multi-stage mass spectrometry. Rapid Commun Mass Spectrom 19:2883-2892.

Tang XJ, Ens W, Standing KG, Westmore JB. 1988. Daughter ion massspectra from cationized molecules of small oligopeptides in a reflecting time-of-flight mass-spectrometer. Anal Chem 60:17911799.

Tao WA, Wollscheid B, O’Brien R, Eng JK, Li X-j, Bodenmiller B, Watts JD, Hood L, Aebersold R. 2005. Quantitative phosphoproteome analysis using a dendrimer conjugation chemistry and tandem mass spectrometry. Nat Meth 2:591-598.

Thaler F, Valsasina B, Baldi R, Jin X, Stewart A, Isacchi A, Kalisz HM, Rusconi L. 2003. A new approach to phosphoserine and phosphothreonine analysis in peptides and proteins: Chemical modification, enrichment via solid-phase reversible binding, and analysis by mass spectrometry. Anal Bioanal Chem 376:366-373.

Thingholm TE, Jensen ON, Larsen MR. 2009. Analytical strategies for phosphoproteomics. Proteomics 9:1451-1468.

Tholey A, Reed J, Lehmann WD. 1999. Electrospray tandem mass spectrometric studies of phosphopeptides and phosphopeptide analogues. J Mass Spectrom 34:117-123.

Ubersax JA, Ferrell JE. 2007. Mechanisms of specificity in protein phosphorylation. Nat Rev Mol Cell Biol 8:665-665.

Villen J, Beausoleil SA, Gygi SP. 2008. Evaluation of the utility of neutralloss-dependent $\mathrm{MS}^{3}$ strategies in large-scale phosphorylation analysis. Proteomics 8:4444-4452.

Wan Y, Cripps D, Thomas S, Campbell P, Ambulos N, Chen T, Yang A. 2008. Phosphoscan: A probability-based method for phosphorylation site prediction using $\mathrm{MS}^{2} / \mathrm{MS}^{3}$ pair information. J Proteome Res 7:28032811.

Weckwerth W, Willmitzer L, Fiehn O. 2000. Comparative quantification and identification of phosphoproteins using stable isotope labeling and liquid chromatography/mass spectrometry. Rapid Commun Mass Spectrom 14:1677-1681.

Wells JM, McLuckey SA. 2005. Collision-induced dissociation (cid) of peptides and proteins. In: Methods Enzymol. Burlington, MA: Elsevier Inc. pp. 148-185.
Wiesner J, Premsler T, Sickmann A. 2008. Application of electron transfer dissociation (ETD) for the analysis of posttranslational modifications. Proteomics 8:4466-4483.

Williamson BL, Marchese J, Morrice NA. 2006. Automated identification and quantification of protein phosphorylation sites by LC/MS on a hybrid triple quadrupole linear ion trap mass spectrometer. Mol Cell Proteomics 5:337-346.

Wolschin F, Lehmann U, Glinski M, Weckwerth W. 2005. An integrated strategy for identification and relative quantification of site-specific protein phosphorylation using liquid chromatography coupled to $\mathrm{MS}^{2} /$ MS $^{3}$. Rapid Commun Mass Spectrom 19:3626-3632.

Woods AS. 2004. The mighty arginine, the stable quaternary amines, the powerful aromatics, and the aggressive phosphate: Their role in the noncovalent minuet. J Proteome Res 3:478-484.

Woods AS, Ferre S. 2005. Amazing stability of the arginine-phosphate electrostatic interaction. J Proteome Res 4:1397-1402.

Woods AS, Moyer SC, Jackson SN. 2008. Amazing stability of phosphatequaternary amine interactions. J Proteome Res 7:3423-3427.

Wysocki VH, Tsaprailis G, Smith LL, Breci LA. 2000. Mobile and localized protons: A framework for understanding peptide dissociation. J Mass Spectrom 35:1399-1406.

Yang XF, Wu HP, Kobayashi T, Solaro RJ, van Breemen RB. 2004. Enhanced ionization of phosphorylated peptides during MALDI TOF mass spectrometry. Anal Chem 76:1532-1536.

Yang F, Wu S, Stenoien DL, Zhao R, Monroe ME, Gritsenko MA, Purvine SO, Polpitiya AD, Tolic N, Zhang Q, Norbeck AD, Orton DJ, Moore RJ, Tang K, Anderson GA, Pasa-Tolic L, Camp DG, Smith RD. 2009. Combined pulsed-q dissociation and electron transfer dissociation for identification and quantification of ITRAQ-labeled phosphopeptides. Anal Chem 81:4137-4143.

Zanivan S, Gnad F, Wickström SA, Geiger T, Macek B, Cox J, Fässler R, Mann M. 2008. Solid tumor proteome and phosphoproteome analysis by high resolution mass spectrometry. J Proteome Res 7:5314-5326.

Zewail AH. 2000. Femtochemistry: Atomic-scale dynamics of the chemical bond. J Phys Chem 104:5660-5694.

Zhou H, Watts JD, Aebersold R. 2001. A systematic approach to the analysis of protein phosphorylation. Nat Biotechnol 19:375-378.

Zubarev RA, Kelleher NL, McLafferty FW. 1998. Electron capture dissociation of multiply charged protein cations. A nonergodic process. J Am Chem Soc 120:3265-3266.

Zubarev RA, Horn DM, Fridriksson EK, Kelleher NL, Kruger NA, Lewis MA, Carpenter BK, McLafferty FW. 2000. Electron capture dissociation for structural characterization of multiply charged protein cations. Anal Chem 72:563-573.

Zubarev RA, Haselmann KF, Budnik B, Kjeldsen F, Jensen F. 2002. Account: Towards an understanding of the mechanism of electron-capture dissociation: A historical perspective and modern ideas. Eur J Mass Spectrom 8:337-349.

Zugaro LM, Reid GE, Ji H, Eddes JS, Murphy AC, Burgess AW, Simpson RJ. 1998. Characterization of rat brain stathmin isoforms by two-dimensional gel electrophoresis matrix assisted laser desorption/ionization and electrospray ionization ion trap mass spectrometry. Electrophoresis 19:867-876. 